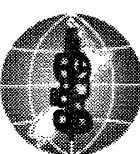

2000

\title{
SEISMIC DESIGN AND RETROFIT OF BRIDGES
}

\author{
Kazuhiko KAWASHIMA ${ }^{1}$
}

\begin{abstract}
SUMMARY
The 1989 Loma Prieta, 1994 Northridge and 1995 Hyogo-ken nanbu earthquakes caused major damage to bridges and these events together with the research triggered as a consequence of the earthquakes has led to significant advances in bridge seismic design and retrofitting. This paper presents how this has affected design philosophies and design codes in EC, New Zealand, Japan and USA in recent years, with emphasis on the Japanese experience in the aftermath of the 1995 H-k-n earthquake. Near field ground motion, linear/nonlinear static/dynamic response analyses, treatment of liquefaction-induced lateral ground movement are described. Comparison of design philosophy, design force and ductility requirements are compared among the EC-8, New Zealand, Japanese, AASHTO and Caltrans/ATC-32 codes. Seismic retrofitting which was conducted in Japan after the Hyogo-ken nanbu earthquake over 29,000 reinforced concrete columns is described.
\end{abstract}

\section{INTRODUCTION}

The extensive damage of highway bridges in the 1989 Loma Prieta, 1994 Northridge and 1995 Hyogo-ken nanbu earthquakes together with the research triggered as a consequence of the recent earthquakes have led to significant advance in bridge seismic design and retrofitting. Near field ground motions developed in the Northridge earthquake and Hyogo-ken nanbu earthquake (H-k-n earthquake) were included in the 1996 Japanese and 1999 Caltrans design codes. The traditional seismic coefficient method is being replaced with the ductility design method, and linear/nonlinear dynamic response analysis is used on routine basis in design of bridges with complex structural response. A new treatment for liquefaction and liquefaction-induced lateral ground movement was included in the Japanese Specifications. Verification of ductility evaluation of reinforced concrete/steel single/frame columns is being conducted in various regions. The displacement-based design was included in the 1999 Caltrans code. Seismic retrofitting has been conducted for over 27,000 reinforced concrete columns, which have inadequate ductility in Japan. Verification for the effectiveness of steel jacket was conducted, and use of new composite materials such as the carbon fiber sheet is being studied.

Countries, which have made significant contributions in developing the seismic design of highway bridges, are, in alphabetic order, Europe, Japan, New Zealand and the United States. Each country has recently revised its seismic bridge code. This paper describes the effect of recent earthquakes on the development of new design practice in those countries, with placing emphasis on the Japanese experience in the aftermath of the $1995 \mathrm{H}-\mathrm{k}-\mathrm{n}$ earthquake.

\section{IMPACT OF THE 1995 HYOGO-KEN-NANBU EARTHQUAKE ON JAPANESE PRACTICE}

\section{Design Specifications}

Because of the unsatisfactory performance of highway bridges in the 1995 Hyogo-ken nanbu earthquake, the Japanese Design Specifications of Highway Bridges were revised in 1996. Some of the main revisions related to 
design force, design of reinforced concrete columns and foundations, and treatment of liquefaction and liquefaction-induced ground movement in the 1996 Specifications are described in the following.

\section{Near Field Ground Motion}

The recent earthquake-damage to bridges and other structures located within a few kilometers from a fault rupture clearly indicated the importance to consider the near-field ground motion effect. As shown in Figure 1, the intensity of acceleration was very high, and was characterized by single pulses with large acceleration and long predominant period. As well as the strong intensity, the directivity of the near-field ground motion is important in seismic design. The pulses with large intensity are generally different in a direction parallel or perpendicular to the fault plane, and depend on the amount and distribution of slip developed on the fault rupture. This is important in considering the effect of bilateral directional excitation. Probably the effect of bilateral excitation for bridges may be considered in terms of difference of ductility capacity of piers [Mahin and Hachem 1999].

Although the ground motion characteristics have been studied based on the measured data, the analytical simulation of near-field ground motions has being developed. For example, Figure 2 shows the predicted ground motion at Motoyama Elementary School that was located in the heavily damaged area in Kobe in the $1995 \mathrm{H}-\mathrm{k}-\mathrm{n}$ earthquake [Kamae and Irikura 1998]. They were synthesized from the after shock records based on the empirical Green's function [Harzel 1978]. Measured records are also presented in Figure 2 for comparison.
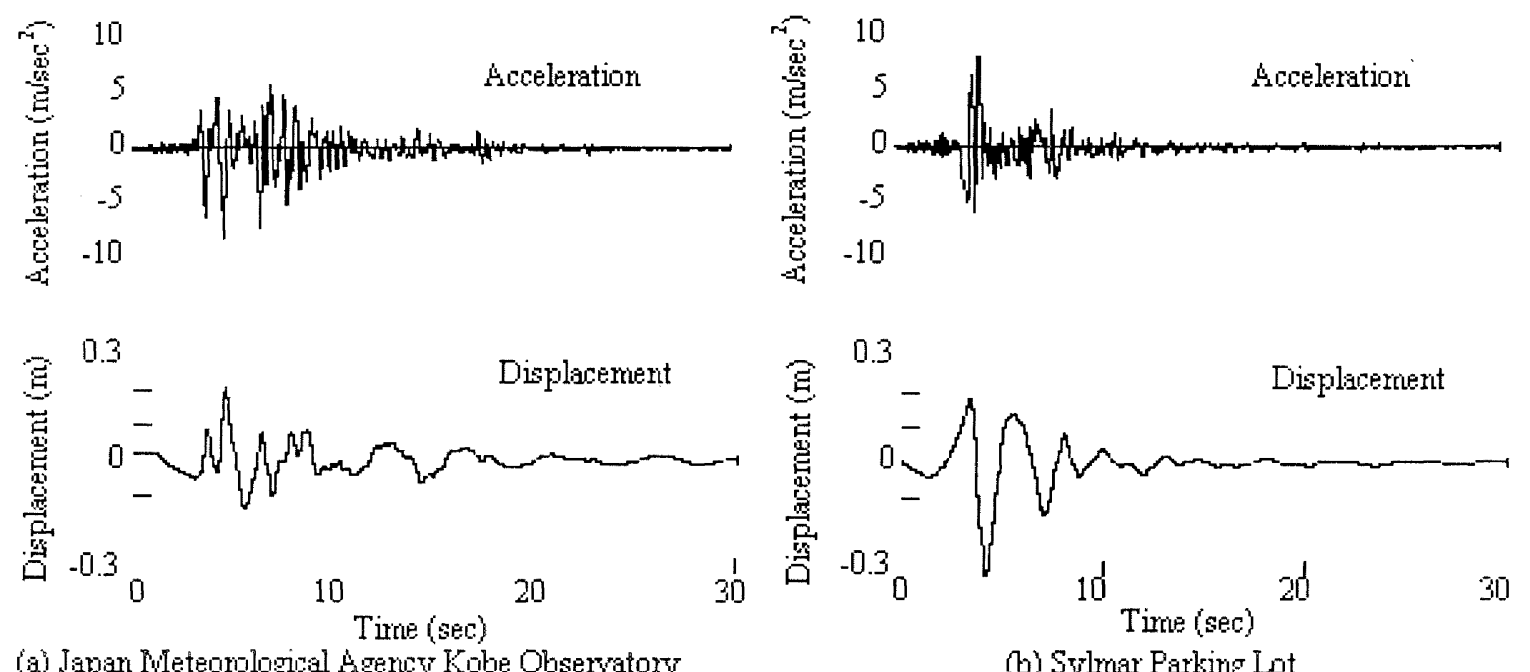

(b) Sylmar Parking Lot

Figure 1 Ground Motions in the 1994 Northridge Earthquake and the 1995 Hyogo-ken Nanbu Earthquake
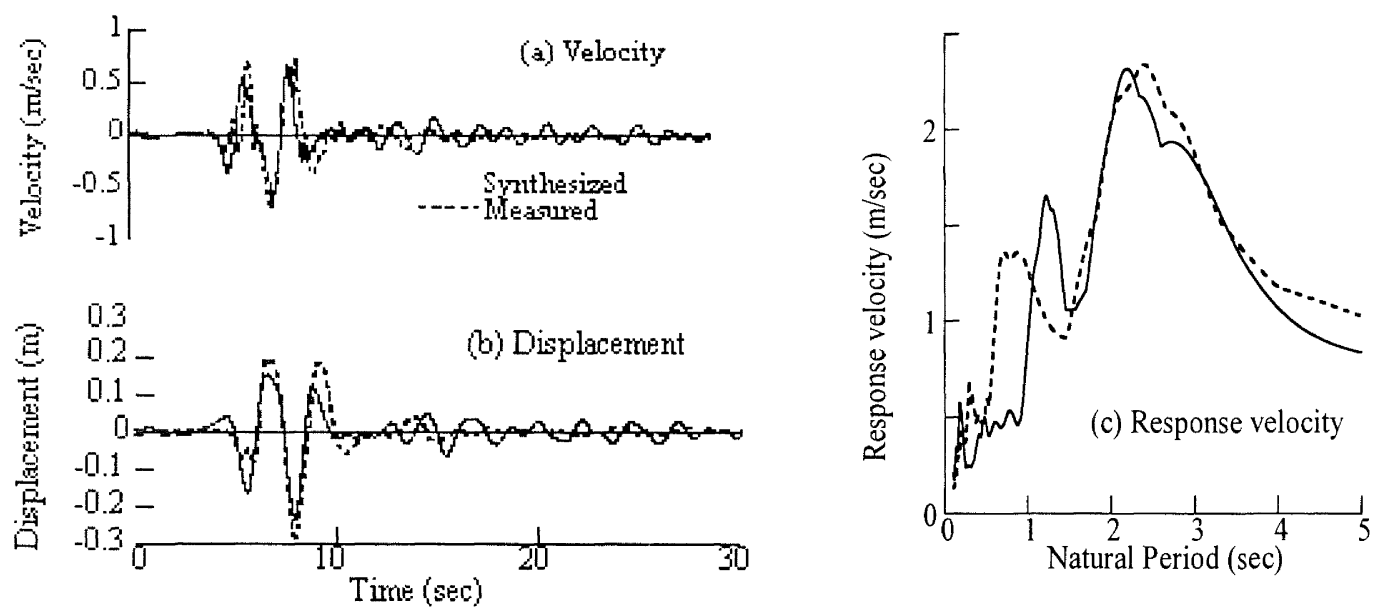

Figure 2 Accuracy of Synthesized Ground Motion Estimated at Motoyama Elementary School, Kobe, in the 1995 Hyogo-ken Nanbu Earthquake [Kamae and Irikura 1998a] 
Quite good agreement is seen between the predicted and measured ground motions. Since the empirical Green's function method has limitation that it can be applied only in cases where appropriate records of small events in the source area are available, a new hybrid simulation method for evaluating near-field ground motions was developed, and it was successfully applied to predict the ground motions in Kobe in the 1995 H-k-n earthquake [Kamae et al. 1998b]. Using the method, the near-field ground motions in the 1948 Fukui earthquake (M7.1), which developed destructive damage in Fukui City, were recently reported [Irikura and Kamae 1999]. It is noteworthy that the predicted peak response velocity of $5 \%$ damping ratio reaches about $7 \mathrm{~m} / \mathrm{s}$ at period of $1.7 \mathrm{~s}$. It suggests that the ground motions in the Northridge and $\mathrm{H}-\mathrm{k}-\mathrm{n}$ earthquakes are not necessarily the strongest. Hence it is important to provide reliable fuse to protect the major parts of bridge system based on the capacity design concept [Priestley et al. 1996].

To represent the near-field ground motion, in addition to the previous Type-I ground motion Type-II ground motion was included in the seismic design code of highway bridges revised in 1996 [JRA 1996]. The Type-II response acceleration of 5\% damping ratio was determined from the response accelerations of the records in Kobe in the H-k-n earthquake as shown in Figure 3 [MOC 1995]. Since shear strain of ground was very large, e.g., over $2 \%$, in the Hyogo-ken nanbu earthquake based on the nonlinear response analysis of ground, it is considered that soft ground behaved as isolators in the seismic isolation at the group III sites. Since such behavior needs further clarification, the design response acceleration at the group III sites was determined in a conservative way as shown in Figure 3. Hence, the Type-II design response acceleration of 5\% damping ratio was provided in the 1996 Specification [JRA 1996] as

$$
S=k_{Z} \cdot k_{D} \cdot\left\{\begin{array}{lc}
S_{7} \cdot T^{2 / 3} & 0 \leq T \leq T_{5} \\
S_{8} & T_{5} \leq T \leq T_{6} \\
S_{9} / T^{5 / 3} & T_{6} \leq T
\end{array} \quad\right. \text { (Type-II Ground Motion) }
$$

in which $k_{Z}=$ zone factor $\left(1.0,0.85\right.$ and 0.7 depending on the region and provided in a map), $k_{D}=$ damping modification factor, $S_{i}(\mathrm{i}=7,8$ and 9$)=$ spectral acceleration $(\mathrm{m} / \mathrm{s})$, and $T_{i}(\mathrm{i}=6,7$ and 8$)=$ limits of constant response acceleration branch (refer to Table 1). The damping modification factor $k_{D}$ is provided as [Kawashima and Aizawa 1986]

$k_{D}=\frac{1.5}{40 \xi+1}+0.5$

Although importance of bridges had been reflected in factoring the design force in terms of the importance factor in the previous Specifications, it was removed from the evaluation of design force. As will be described later, it is accounted in the evaluation of allowable displacement ductility factor.

It should be noted that the Type-II response acceleration is used for safety-evaluation in design together with the following response accelerations for functional-evaluation and safety evaluation.

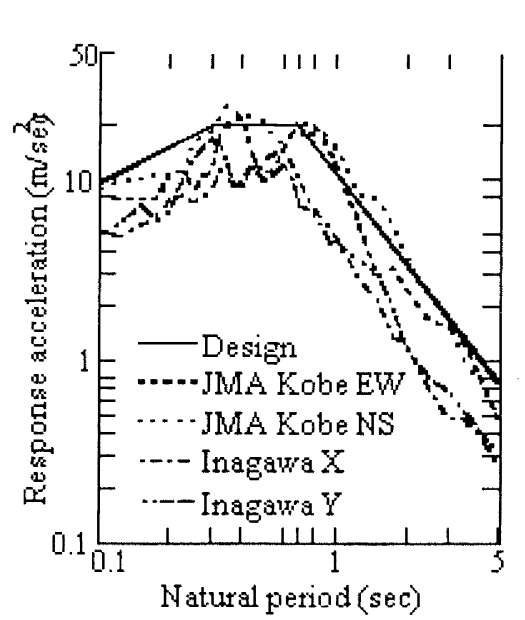

(a) Group-I

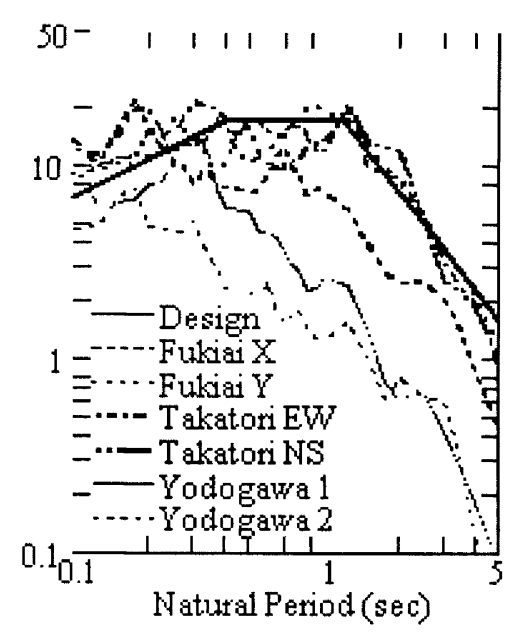

(b) Group-II

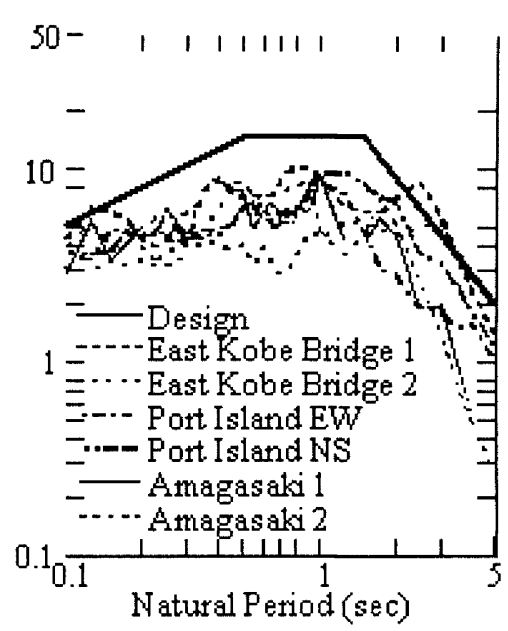

(c) Group-III

Figure 3 Type-II Ground Motions Determined from the 5\% Damped Response Accelerations of the Records in Kobe, 1995 Hyogo-ken Nanbu Earthquake 
Function-Evaluation

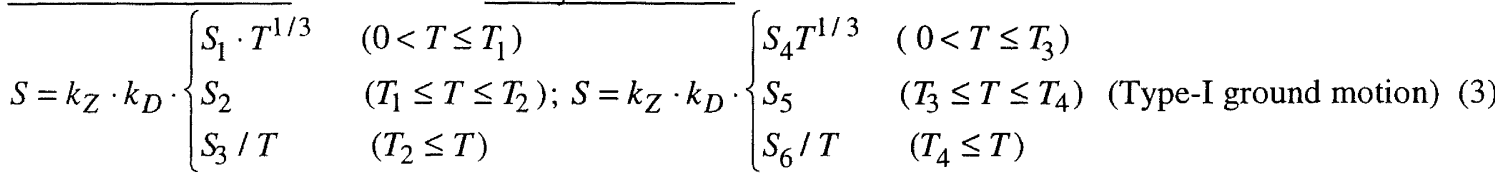

in which $S_{i}(\mathrm{i}=1-6)$ and $T_{i}(\mathrm{i}=1-4)$ are shown in Table 1.

Figure 4 (a) shows the response acceleration $S$ in Eqs. (1) and (3). Thus including the near-field ground motion, two-level design force with three ground motions is used in design of Japanese highway bridges after the H-k-n earthquake. Type-I ground motion intends to represent the ground motion, which was developed in Tokyo in the 1923 Kanto earthquake (M7.9). Because of the large number of victims ever experienced in Japan (about 140,000 were killed), the Kanto earthquake has been regarded a special earthquake. The safety-evaluation ground motion (Type-I) in Eqn. (3) was deterministically evaluated assuming a combination of $\mathrm{M}=8$ and the epicentral distance $=50 \mathrm{~km}$ based on an attenuation equation of response acceleration which was developed based on the statistical analysis of 394 components of free-field Japanese ground motions [Kawashima et al. 1984]. Other empirical experience as well as the practice in buildings was also included in establishing the safetyevaluation ground motion in Eqn. (3).

Equivalent lateral force coefficient of $0.2-0.3$ has been traditionally used based on the allowable stress design approach since 1926. Because enough scientific knowledge on the ground motion and structural response with nonlinear behavior was not available at those days, and because it has been certainly effective to mitigate seismic damage of bridges and other structures in the past earthquakes, it had been regarded that the combination of lateral force coefficient of 0.2-0.3 and the allowable stress design approach provided sufficient countermeasures under the 1923 Kanto earthquake-type design earthquake.

Table 1 Values of Parameter in Eqs. (1) and (3)

(a) Function-Evaluation Ground Motion

\begin{tabular}{|c|c|c|c|c|c|}
\hline Soil Group & $T_{1}(\mathrm{~s})$ & $T_{2}(\mathrm{~s})$ & $S_{1}\left(\mathrm{~m} / \mathrm{s}^{2}\right)$ & $S_{2}\left(\mathrm{~m} / \mathrm{s}^{2}\right)$ & $S_{3}\left(\mathrm{~m} / \mathrm{s}^{2}\right)$ \\
\hline I & 0.1 & 1.1 & 4.31 & 2.0 & 2.2 \\
\hline II & 0.2 & 1.3 & 4.27 & 2.5 & 3.25 \\
\hline III & 0.34 & 1.5 & 4.3 & 3.0 & 4.5 \\
\hline
\end{tabular}

(b) Safety-Evaluation Ground Motions

\begin{tabular}{|c|c|c|c|c|c|c|c|c|c|c|}
\hline \multirow{2}{*}{$\begin{array}{c}\text { Soil } \\
\text { Group }\end{array}$} & \multicolumn{9}{|c|}{ Type I Ground Motion } & \multicolumn{5}{c|}{ Type II Ground Motion } \\
\cline { 2 - 11 } & $T_{3}(\mathrm{~s})$ & $T_{4}(\mathrm{~s})$ & $S_{4}\left(\mathrm{~m} / \mathrm{s}^{2}\right)$ & $S_{5}\left(\mathrm{~m} / \mathrm{s}^{2}\right)$ & $S_{6}\left(\mathrm{~m} / \mathrm{s}^{2}\right)$ & $T_{5}(\mathrm{~s})$ & $T_{6}(\mathrm{~s})$ & $S_{7}\left(\mathrm{~m} / \mathrm{s}^{2}\right)$ & $S_{8}\left(\mathrm{~m} / \mathrm{s}^{2}\right)$ & $S_{9}\left(\mathrm{~m} / \mathrm{s}^{2}\right)$ \\
\hline I & 0 & 1.4 & - & 7.0 & 9.8 & 0.3 & 0.7 & 44.63 & 20.0 & 11.04 \\
\hline II & 0.18 & 1.6 & 15.05 & 8.5 & 13.6 & 0.4 & 1.2 & 32.24 & 17.5 & 23.71 \\
\hline III & 0.29 & 2.0 & 15.11 & 10.0 & 20.0 & 0.5 & 1.5 & 23.81 & 15.0 & 29.48 \\
\hline
\end{tabular}

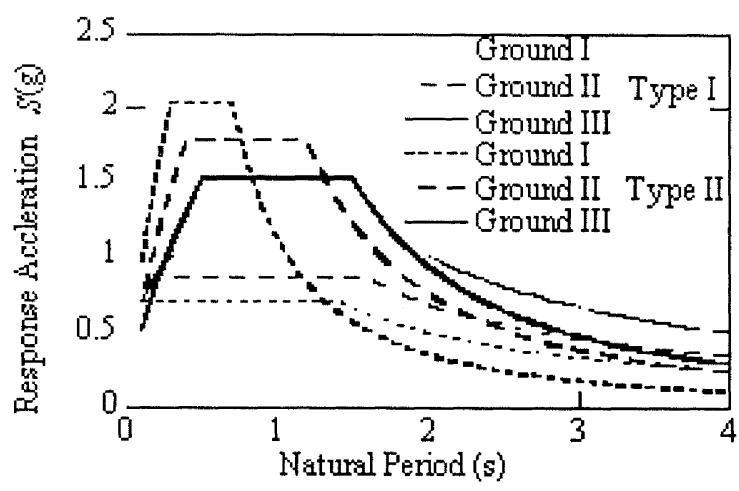

(a) Resporse acceleration by Eqs. (1) and (3)

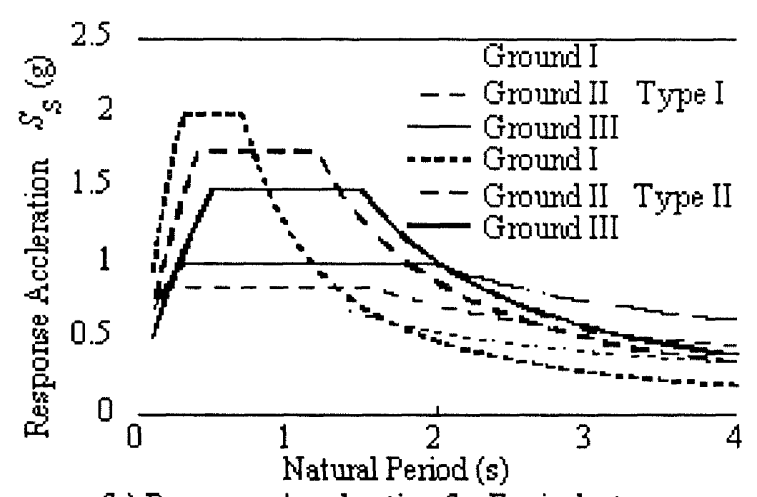

(b) Response Acceleration for Equivalent Static Analysis Sby Eq. (5)

Figure 4 Response Accelerations of Japanese Highway Bridges 
One of the unique points of the Japanese design force is that the elastic response accelerations used for the equivalent static analysis includes the modification for talking account of damping ratio of bridges [Kawashima, 1994]. Based on the forced excitation test of bridges, an empirical relation was obtained for the small-amplitude natural period $T$ dependence of damping ratio $\xi$ of bridges as $\xi=0.02 / T$ [Kuribayashi and Iwasaki, 1972]. Substituting this relation through Eqn. (2) into Eqs. (1) and (3), after re-fitted by straight lines, one obtains the elastic response accelerations for the equivalent static analysis $S_{s}$ as

$\underline{\text { Functional -evaluation }}$

$$
S_{s}=k Z \cdot\left\{\begin{array}{lc}
S_{s 1} \cdot T^{1 / 3} & 0<T \leq T_{1} \\
S_{s 2} & T_{1} \leq T \leq T_{2} \\
S_{s 3} / T^{2 / 3} & T_{2} \leq T
\end{array}\right.
$$

Safety-evaluation

$$
S_{s}=k_{Z} \cdot\left\{\begin{array} { l l } 
{ S _ { s 4 } T ^ { 1 / 3 } } & { 0 < T \leq T _ { 3 } } \\
{ S _ { s 5 } } & { T _ { 3 } \leq T \leq T _ { 4 } } \\
{ S _ { s 6 } / T ^ { 2 / 3 } } & { T _ { 4 } \leq T }
\end{array} \quad \left(\text { Type-I GM); } S_{e}=k_{Z} \cdot\left\{\begin{array}{ll}
S_{s 7} T^{2 / 3} & 0<T \leq T_{5} \\
S_{s 8} & T_{5} \leq T \leq T_{6} \\
S_{s 9} / T^{4 / 3} & T_{6} \leq T
\end{array} \quad\right. \text { (Type-II GM) }\right.\right.
$$

in which $S_{s i}(i=1-9)=$ spectral acceleration $(\mathrm{m} / \mathrm{s})$, and given in Table 2. Natural periods $T_{i}(i=1-6)$ that represent the limits of the constant response acceleration are the same with those in Eqs. (1) and (3). However, the gradient at the constant velocity ranges in Eqs. (4) and (5) is smaller than that in Eqs. (1) and (3) by a factor of $T^{1 / 3}$ as a consequence of smaller damping ratio at the constant response velocity range. Figure 4 (b) shows the response accelerations $S_{s}$ by Eqs. (4) and (5).

\begin{tabular}{|c|c|c|c|c|c|c|c|c|c|}
\hline \multirow{3}{*}{$\begin{array}{c}\text { Soil } \\
\text { Group }\end{array}$} & \multirow{2}{*}{\multicolumn{3}{|c|}{ Function-Evaluation }} & \multicolumn{6}{|c|}{ Safety-Evaluation } \\
\hline & & & & \multicolumn{3}{|c|}{ Type-I Ground Motion } & \multicolumn{3}{|c|}{ Type-II Ground Motion } \\
\hline & $S_{s 1}\left(\mathrm{~m} / \mathrm{s}^{2}\right)$ & $S_{s 2}\left(\mathrm{~m} / \mathrm{s}^{2}\right)$ & $S_{s 3}\left(\mathrm{~m} / \mathrm{s}^{2}\right)$ & $S_{s 4}\left(\mathrm{~m} / \mathrm{s}^{2}\right)$ & $S_{s 5}\left(\mathrm{~m} / \mathrm{s}^{2}\right)$ & $S_{s 6}\left(\mathrm{~m} / \mathrm{s}^{2}\right)$ & $S_{s 7}\left(\mathrm{~m} / \mathrm{s}^{2}\right)$ & $S_{s 8}\left(\mathrm{~m} / \mathrm{s}^{2}\right)$ & $S_{s 9}\left(\mathrm{~m} / \mathrm{s}^{2}\right)$ \\
\hline I & 4.22 & 1.96 & 2.09 & - & 6.86 & 8.58 & 43.7 & 19.6 & 12.15 \\
\hline II & 4.18 & 2.45 & 2.92 & 14.8 & 8.33 & 11.37 & 31.8 & 17.15 & 21.85 \\
\hline III & 4.21 & 2.94 & 3.85 & 14.8 & 9.8 & 15.58 & 23.3 & 14.7 & 25.2 \\
\hline
\end{tabular}

Table 2 Values of Parameter in Eqs. (4) and (5)

\section{Design of Piers}

In the $1995 \mathrm{H}-\mathrm{k}-\mathrm{n}$ earthquake, a number of reinforced concrete piers suffered damage due to flexure-shear failure at midheight as a consequence of premature termination of the longitudinal reinforcement. Bar termination was determined based on the design moment distribution, without accounting for the effect of tension shift due to diagonal shear cracking. This resulted in a short development length of reinforcements lap spliced at midheight. This practice had been used until it was revised in 1980 [JRA 1980]. Failure of the 18-spans of the collapsed Hanshin Expressway was triggered by this deficiency (refer to Photo 1)[MOC 1995]. Furthermore, the allowable shear stress had been over-estimated and the confinement was poor.

Important point is that vulnerability of reinforced concrete piers associated with the above three deficiencies was not widely recognized prior to the $\mathrm{H}-\mathrm{k}-\mathrm{n}$ earthquake, since bridges have not been collapsed for long time prior to the H-k-n earthquake. The Ministry of Construction conducted nation-wide seismic inspection for highway bridges five times, i.e., in 1971, 1976, 1979, 1986 and 1991, by gradually expanding the items of inspection from deterioration to vulnerability of collapse [JRA 1987, Kawashima et al. 1994]. It was the 1982 Urakawa-oki earthquake when the flexure-shear failures at pier mid-height as a consequence of premature termination of longitudinal reinforcement was first recognized [Narita et al. 1983]. Seismic evaluation for the flexure-shear failure was included in the 1991 inspection, and several tens of reinforced concrete piers were retrofitted by the steel jacketing in the Metropolitan and Hanshin Expressways prior to the H-k-n earthquake. The retrofitted piers performed well in the H-k-n earthquake [Sato et al. 1997]. But the portion of Hanshin Expressway that suffered damage in the H-k-n earthquake had not yet been retrofitted.

As a consequence of the H-k-n earthquake, the Design Specifications of Highway Bridges were extensively revised in 1996 [JRA 1996]. The ductility check of reinforced concrete piers which was included in the 1990 Design Specifications was upgraded to the "ductility design method" which applies to every structural 
components in which seismic effect is predominant. In ordinary bridges, a bridge is designed assuming a principal plastic hinge at bottom of pier so that the following requirement is satisfied.

$P_{a} \geq S_{e s} W / g$

in which $P_{a}=$ lateral capacity of a pier, $S_{e s}=$ equivalent response acceleration and $W$ =tributary weight. Assuming the equal energy principle, $S_{e s}=S_{s} / \sqrt{2 \mu_{a}-1}$, in which $\mu_{a}$ =allowable displacement ductility factor of the pier and $S_{s}=$ elastic response acceleration for the equivalent static analysis by Eqn. (5). Since the maximum $\mu_{a}$ for a single reinforced concrete piers is 8 , the response modification factor $R=\sqrt{2 \mu_{a}-1}$ is smaller than 3.8 .

Pier strength and allowable ductility factor $\mu_{a}$ are determined depending on the failure mode. Flexural strength is evaluated from the standard moment vs. curvature analysis. Fiber-element-analysis is conducted for every pier assuming a stress vs. strain relation of concrete and reinforcing bars. The stress vs. strain relation of reinforcing bars is idealized by an elastic-perfect plastic model, while, the stress vs. strain relation of confined concrete is given as [Hoshikuma et al. 1997]

$$
f_{c}= \begin{cases}E_{c} \varepsilon_{c}\left\{1-\frac{1}{n}\left(\frac{\varepsilon_{c}}{\varepsilon_{c c}}\right)^{n-1}\right\} & \left(0 \leq \varepsilon_{c} \leq \varepsilon_{c c}\right) \\ f_{c c}-E_{d e s}\left(\varepsilon_{c}-\varepsilon_{c c}\right) & \left(\varepsilon_{c c} \leq \varepsilon_{c} \leq \varepsilon_{c u}\right)\end{cases}
$$

in which $f_{c c}$ and $\varepsilon_{c c}=$ strength of confined concrete and strain corresponding to $f_{c c}, E_{c}=$ elastic modulus of concrete, $E_{d e s}=$ gradient at descending branch, and $n=E_{c} \varepsilon_{c c} /\left(E_{c} \varepsilon_{c c}-f_{c c}\right)$. In Eq. (7), $f_{c c}, \varepsilon_{c c}$ and $E_{d e s}$ are provided as

$$
f_{c c}=f_{c 0}+3.8 \alpha \rho_{s} f_{s y} ; \varepsilon_{c c}=0.002+0.033 \beta \frac{\rho_{s} f_{s y}}{f_{c 0}} ; E_{d e s}=11.2 \frac{f_{c 0}^{2}}{\rho_{s} \cdot f_{s y}}
$$

in which $f_{c 0}=$ design strength of concrete, $f_{s y}=$ yield strength of reinforcements, $\alpha$ and $\beta$ = shape factors ( $\alpha=1.0$ and $\beta=1.0$ for circular piers, and $\alpha=0.2$ and $\beta=0.4$ for rectangular piers), and $\rho_{s}=$ volumetric ratio of tie reinforcements.

The ultimate displacement $d_{u}$ is defined as the displacement at the gravity center of superstructure when concrete compression strain at the out-most reinforcements reaches the following ultimate strain $\varepsilon_{c u}$;

$\varepsilon_{c u}= \begin{cases}\varepsilon_{c c} & \text { (Type - I ground motion) } \\ \varepsilon_{c c}+0.2 f_{c c} / E_{d e s} & \text { (Type - II ground motion) }\end{cases}$

It should be noted in Eqn. (9) that the ultimate concrete strain depends on the type of ground motion. The deterioration of reinforced concrete pier at the plastic hinge region is larger under cyclic loading with large number of inelastic excursions (Type-I ground motion) as compared to cyclic loading with small number of inelastic excursions (Type-II ground motion) [for example, Takemura and Kawashima, 1997]. Taking account of such ground motion-dependent deterioration of piers, the ultimate concrete compression strain is assumed to be $\varepsilon_{c c}$ under the Type-I ground motion, while it is assumed to be the strain corresponding to the stress $20 \%$ deteriorated from the maximum stress $f_{c c}$. Thus, the ultimate displacement of a pier is larger under the Type-II loading than the Type-I loading.

The ultimate displacement $d_{u}$ of a pier is evaluated from yielding and ultimate curvatures $\phi_{y}$ and $\phi_{u}$ as [Priestley and Park 1987, Priestley at al. 1996]

$d_{u}=d_{y}+\left(\phi_{u}-\phi_{y}\right)\left(h-L_{p} / 2\right) L_{p}$

in which $h=$ height of the pier and $L_{p}=$ plastic hinge length $\left(L_{p}=0.2 h-0.1 D ; 0.1 D \leq L_{p} \leq 0.5 D\right)$.

On the other hand, shear strength of a reinforced concrete pier $P_{s}$ is evaluated as

$P_{s}=V_{c}+V_{s}$

where

$V_{c}=k_{c} \cdot k_{e} \cdot k_{p t} \cdot v_{c} \cdot b \cdot h ; V_{s}=A_{w} \cdot f_{s y} \cdot d \cdot(\sin \theta+\cos \theta) /(1.15 \cdot a)$

in which $V_{c}$ and $V_{s}=$ shear strength of concrete and transverse reinforcement, $v_{c}=$ shear strength of concrete (e.g., $0.35 \mathrm{MPa}$ and 0.37 MPA for concrete with design strength of $24 \mathrm{MPa}$ and $30 \mathrm{MPa}$, respectively), $k_{c}=$ cyclic loading effect factor, $k_{e}=$ effective height factor (e.g., 1.0, 0.7, 0.6 and 0.5 for effective height of < $1 \mathrm{~m}, 3 \mathrm{~m}, 5 \mathrm{~m}$ and $>10 \mathrm{~m}$, respectively), $k_{p t}=$ modification factor depending on tension bars ratio $p_{t}$ (e.g., $0.9,1.0$, 
1.2 and 1.5 for tension reinforcement ratio of $0.2 \%, 0.3 \%, 0.5 \%$ and $>1.0 \%), b$ and $h$ =effective width and height, and $A_{w}=$ area of reinforcing bars with an interval $a$ and an angle $\theta$. The factor $k_{c}$ in Eqn. (12) represents the deterioration of shear strength under cyclic loading. It is recommended to be $1.0,0.6$ and 0.8 under static loading, Type-I ground motion and Type-II ground motion, respectively. Shear strength of concrete $P_{s}$ under static loading $\left(k_{c}=1.0\right)$ is denoted $P_{s 0}$.

Based on the flexural strength $P_{f u}$, shear strength $P_{s}$ and shear strength under static loading $P_{s 0}$, failure mode of a pier is decided to be one of the flexural failure, shear failure after flexural damage and shear failure as

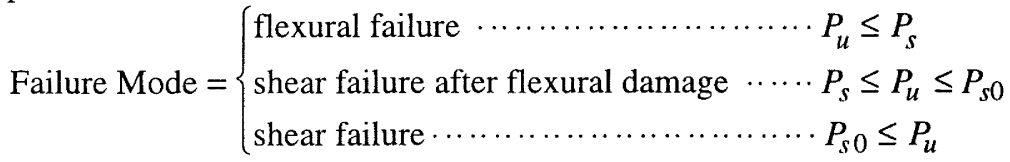

, and the lateral capacity $P_{a}$ and the allowable displacement ductility factor $\mu_{a}$ in Eqn. (6) are provided as

$P_{a}=\left\{\begin{array}{lll}P_{u} & \cdots \cdots & \text { flexural failure }+ \text { shear failure after flexural damage } \\ P_{s 0} & \cdots \cdots & \text { shear failure }\end{array}\right.$

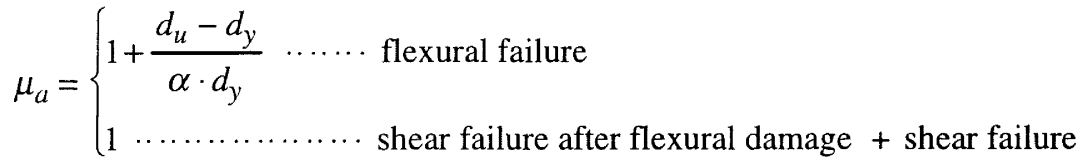

in which $\alpha$ =safety factor depending on importance of bridges and the type of ground motion ( $\alpha=3.0$ and 2.4 for important and ordinary bridges, respectively, under the Type-I ground motions, and $\alpha=1.5$ and 1.2 for important and ordinary bridges, respectively, under the Type-II ground motions), $d_{y}$ and $d_{u}=$ yielding and ultimate displacement of the pier. Larger $\alpha$-value is assigned for bridges with higher importance under cyclic loading with long duration (Type-I ground motion). Thus, in addition to the determination of ultimate displacement $d_{u}$, the ground motion characteristics are also accounted in the evaluation of the allowable displacement ductility factor of a piers $\mu_{a}$.

A number of reinforced concrete piers that suffered flexural failure at their based did not collapse, but tilted and were left with large residual displacement at the top. About 100 piers with a tilt angle of more than 1 degree $(1.75 \%$ drift) were demolished and new piers were built due to the difficulty of setting the superstructures back to the original alignments and levels. Residual displacements in piers have been considered to be secondary importance to maximum ductility demand in seismic design of structures. Residual displacement should be considered independently from maximum ductility because a wide range of residual displacement may occur for the same ductility demand. Hence, a requirement of residual displacement $d_{R}$ developed at a pier after an earthquake was first included in the 1995 Specifications as

$d_{R} \leq d_{R a}$

where

$d_{R}=c_{R}\left(\mu_{r}-1\right)(1-r) d_{y} ; \quad \mu_{r}=1 / 2 \cdot\left[\left\{S_{s} /\left(g \cdot P_{a}\right)\right\}^{2}+1\right]$

in which $d_{R a}=$ allowable residual displacement, $r$ =bilinear factor defined as a ratio between the first stiffness (yield stiffness) and the second stiffness (post-yield stiffness) of the pier, $c_{R}=$ factor depending on the bilinear factor $r, \mu_{r}=$ response displacement ductility factor of the pier, and $d_{y}$ =yielding displacement of the pier. $c_{R}$ was set 0.5 for reinforced concrete piers based on the residual displacement response spectrum [Kawashima et al. 1998]. The $d_{R a}$ is $1 \%$ of the distance between bottom of the pier and the gravity center of the superstructure ( $1 \%$ drift).

As the design details, various requirements for confinement were added. For example, size of tie bars has to be $13 \mathrm{~mm}$ or larger in diameter, and they are provided in each $150 \mathrm{~mm}$ or shorter. In tall piers ( $>30 \mathrm{~m}$ ), it can be extended to $300 \mathrm{~mm}$ at the region outside 4 times the plastic hinge length, but the space should be gradually changed. Cross ties with the same size with main bars are required at spacing of $150 \mathrm{~mm}$ or shorter (same spacing with the tie bars). They are placed at distance of no larger than $1 \mathrm{~m}$.

It is interesting to evaluate how much changes were induced as a consequence of the revisions of codes. A few bridges were designed according to the past and current codes, assuming that only pier size and reinforcements were changed by keeping the superstructure, pier height and soil condition the same. Figure 5 compares the section of a $11 \mathrm{~m}$ high reinforced concrete pier that supports a part (4.97 MN weight) of 3-span continuous steel 
girder bridge with 3@40 m long. Ground condition was Group-II (moderate). The pier designed according to the 1964 Specifications, which were used in design of most bridges that suffered damage in the H-k-n earthquake

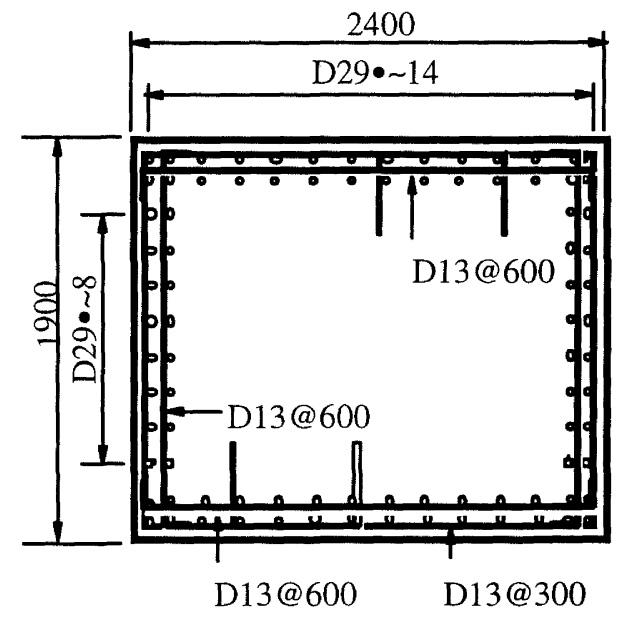

(a) 1964 Specifications

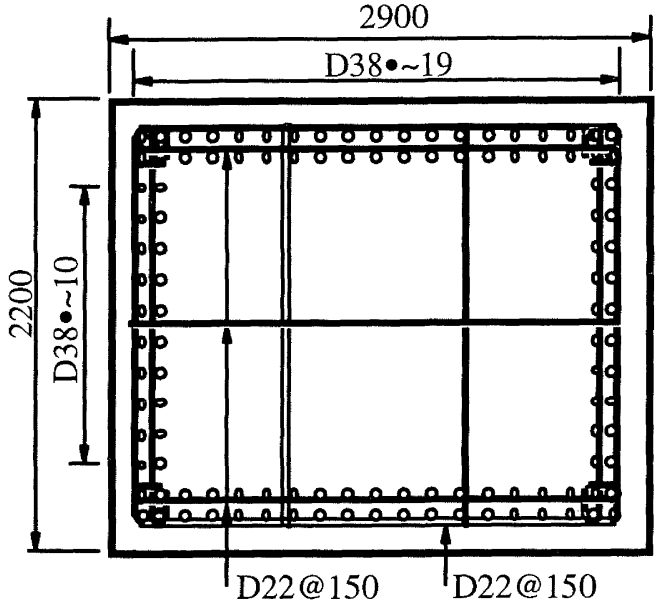

(b) 1996 Specifications

Figure 5 Comparison of Column Sections Designed According to the 1964 and 1999 Design Specifications

including the collapsed 18-span bridge, is $2.4 \mathrm{~m}$ wide (transverse direction) and $1.9 \mathrm{~m}$ high (longitudinal direction). It is reinforced by 88 deformed bar with $29 \mathrm{~mm}$ diameter (D29) in double (reinforcement ratio $=1.24 \%$ ), and D13 ties are provided in each $300 \mathrm{~mm}$ and $600 \mathrm{~mm}$ for the outside and inside bars, respectively. Thus the volumetric ratio of ties $\rho_{s}$ is only $0.08 \%$ and $0.1 \%$ in longitudinal and transverse directions, respectively. On the other hand, the pier design according to the 1996 Design Specifications is $2.9 \mathrm{~m}$ wide and $2.2 \mathrm{~m}$ high. It is reinforced by 116 D38 bards in double (reinforcement ratio=2.07\%) and D22 ties are provided in each $150 \mathrm{~mm}$ for both outside and inside bars. The tie reinforcement ratio $\rho_{s}$ is thus $1.15 \%$ and $1.08 \%$ in longitudinal and transverse directions, respectively.

If the pier designed according to the 1964 Specifications is evaluated according to the current Specifications, it fails in shear based on Eqn. (13), because the shear strength by Eqn. (11) is $1.78 \mathrm{MN}$ while the flexural strength is $1.87 \mathrm{MN}$ in longitudinal direction. On the other hand, the shear and flexural strengths of the pier designed according to the current Specifications are 11.33 MN and 4.32 MN, respectively in longitudinal direction. Hence, it fails in flexure. Since the ultimate displacement ductility factor $\mu_{u}=d_{u} / d_{y}$ computed from the standard moment-curvature analysis under the Type-II ground motion (Type-II ground motion was predominant in this example) is 5.4, the allowable displacement ductility factor $\mu_{a}$ is 3.93 from Eqn. (15). Natural period of the pier-superstructure system taking account of foundation flexibility is 0.73 second. Since the response acceleration for safety-evaluation in Type-II at this natural period is $17.5 \mathrm{~m} / \mathrm{s}^{2}$ from Eqn. (5), dividing this value by the seismic modification factor $R=\sqrt{2 \mu_{a}-1}=2.62$, the equivalent response acceleration $S_{e s} \equiv S_{s} / R$ becomes $6.7 \mathrm{~m} / \mathrm{s}^{2}$. Since the tributary weight of this pier is $6.15 \mathrm{MN}$, the lateral force demand is $6.7 \times 6.15$ $\mathrm{MN} / \mathrm{g}=4.1 \mathrm{MN}$. Since the flexural capacity of the pier (4.32 MN) is larger than the demand, this pier is safe in longitudinal direction. Similar evaluation shows that the pier is also safe in transverse direction. The residual displacement from Eqn. (17) is $80 \mathrm{~mm}$ and $90 \mathrm{~mm}$ in longitudinal and transverse directions, respectively. They are smaller than the $1 \%$ drift $(110 \mathrm{~mm})$.

\section{Design of Foundation}

Push-over analysis was included for design of foundations under safety-evaluation ground motion in the 1996 Specifications. In the push over analysis, a foundation is modeled as a structure supported by ground. For example, in a pile foundation, the piles and footing are idealized to be supported by nonlinear soil springs as shown in Figure 6. As well as the plastic deformation of piles, the nonlinear deformation of soils around the piles, and uplift and pull-down of piles are taken into account. Evaluation of spring stiffness and strength are presented in the Design Specifications [JRA 1996].

Design lateral force for a foundation $P_{F}$ is evaluated from the lateral capacity of the pier $P_{a}$ by Eqn. (14) as

$P_{F}=k_{F} P_{a}$ 
in which $k_{F}$ is the over-strength factor $(=1.1)$. Under the design lateral force, the foundation is designed so that it does not yield. The yielding of foundations is defined depending on the type of foundations. In a pile

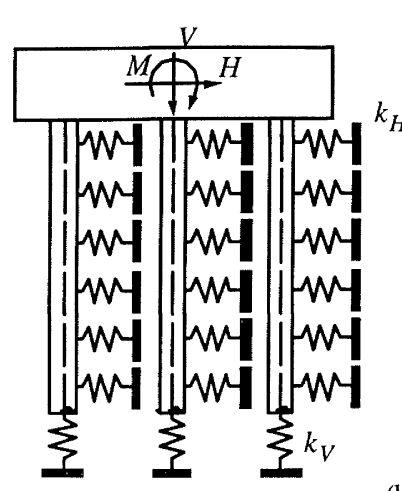

(a) Analytical model

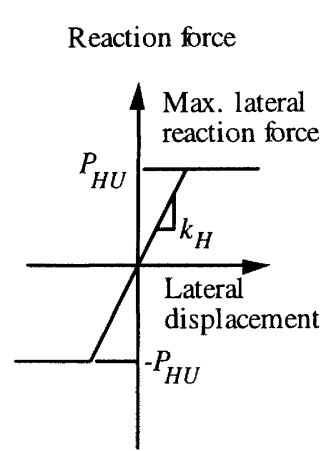

(b) Lateral force vs. lateral displacement relation

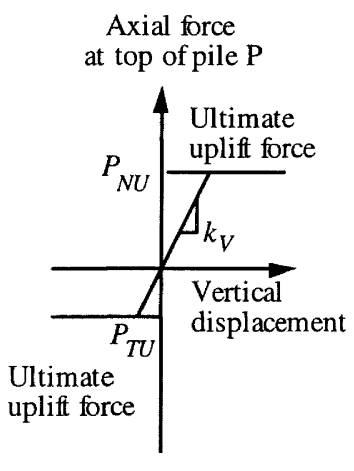

(c) Vertical force vs. vertical displacement relation

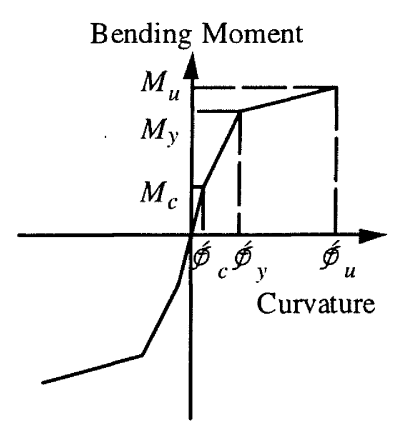

(d) Moment vs. curvature relation

Figure 6 Model for Design of Pile Foundation under Safety-Evaluation Ground Motion

foundation, the yielding is defined as the stage when either of the following occurs first;

- All piles yield.

- Compression force, which applies to the piles on a same line, reaches the strength of ground.

The above conditions result in sudden deterioration of the lateral resistance of the pile foundation. Although the upward force, which applies to piles, is also important for the lateral resistance, it is not included as the stage of the yield, because this does not cause critical deterioration due to the dead weight effect.

\section{Liquefaction and Liquefaction-Induced Ground Movement}

Extensive soil liquefaction occurred over a wide area in offshore reclaimed lands and natural deposits in the H-k$\mathrm{n}$ earthquake. Liquefaction occurred in not only sandy layers but also gravel layers with averaged grain size over $2 \mathrm{~mm}$. Such gravel layers had been regarded free from liquefaction in the past. Liquefaction resulted in the ground movement in horizontal direction near shorelines. It was found from aerial photographs that the liquefaction-induced ground movement reached as large as 3-4 m [Hamada et al. 1995]. Several bridges suffered extensive damage due to liquefaction-induced ground movement [MOC 1996, Tamura et al. 2000].

After experiencing the H-k-n earthquake, the evaluation of liquefaction potential and its treatment were extensively revised. The $F_{L}$-method [Iwasaki 1985] was revised so that it is evaluated under the safety-evaluation ground motion. The type of ground motion dependency of the shear strength of soil was included. Soils which require the evaluation of liquefaction potential based on the $F_{L}$-method was extended to include gravel layers; saturated ground within $20 \mathrm{~m}$ from the ground surface and where water table is within $10 \mathrm{~m}$ from the ground surface; soil layers with fine content $\mathrm{FC}<35 \%$, or soils with FC $>35 \%$ and the plasticity index $I_{p}<15$; and soil layers with $D_{50}<10 \mathrm{~mm}$ and $D_{10}<1 \mathrm{~mm}$, in which $D_{50}$ and $D_{10}$ are the grain size corresponding to $50 \%$ and $10 \%$ on the accumulation grain size curve.

In the above soil layers, the liquefaction potential factor $F_{L}$ is evaluated based on cyclic shear stress ratio $R$ and cyclic shear strength ratio $L$ as

$F_{L}=R / L$

where

$R=c_{G M} R_{L} ; L=r_{d} k_{h c} \sigma_{v} / \sigma_{v}$

in which $R_{L}=$ tri-axial strength ratio of soil, $k_{G M}=$ type of ground motion factor, $k_{d}=$ acceleration reduction factor in underground $\left(k_{d}=1.0-0.015 x\right.$ where $x$ is the depth $\left.(\mathrm{m})\right), a_{g}=$ acceleration at ground surface in the Type-I and Type-II ground motions, and $\sigma_{v}$ and $\sigma_{v}{ }^{\prime}=$ total and effective overburden pressure. $a_{g}$ is $0.3 \mathrm{~g}, 0.35 \mathrm{~g}$ and $0.4 \mathrm{~g}$ at the ground groups I, II and III, respectively, under the Type-I ground motion, and $0.8 \mathrm{~g}, 0.7 \mathrm{~g}$ and $0.6 \mathrm{~g}$ at the ground groups I, II and III, respectively, under the Type-II ground motion. Ground motion type dependency of the shear strength of soils is accounted by $k_{G M}$ as 
$k_{G M}=\left\{\begin{array}{ll}1.0 & \left(R_{L} \leq 0.1\right) \\ 1.0 & \left(0.1<R_{L} \leq 0.4\right) \\ 3.3 R_{L}+0.67 & \left(0.4<R_{L}\right) \\ 2.0 & \text { (Type- I ground motion) }\end{array} \quad\right.$ (Type - II ground motion)

The tri-axial strength ratio $R_{L}$ in Eqn. (21) is represented as

$R_{L}= \begin{cases}0.0882 \sqrt{N_{a} / 1.7} & \left(N_{a}<14\right) \\ 0.0882 \sqrt{N_{a} / 1.7}+1.6 \times 10^{-6} \cdot\left(N_{a}-14\right) & \left(14 \leq N_{a}\right)\end{cases}$

where

$N_{a}= \begin{cases}c_{1} \frac{1.7 N}{\sigma_{v}+0.7}+c_{2} & \text { (Sand) } \\ \left\{1-0.36 \log _{10}\left(D_{50} / 2\right)\right\} N_{1} & \text { (Gravels) }\end{cases}$

in which $N, N_{a}$ and $N_{1}=N$-value of standard penetration test, corrected $N$-value accounting for the effect of grain size, and $N$-value corresponding to overburden soil pressure of $0.1 \mathrm{MPa}\left(1 \mathrm{kgf} / \mathrm{cm}^{2}\right)$, and coefficients $c_{1}$ and $c_{2}$ are given as

$c_{1}=\left\{\begin{array}{ll}1 & (0 \leq F C<10 \%) \\ (F C+40) / 50 & (10 \% \leq F C<60 \%) ; c_{2} \\ F C / 20-1 & (60 \% \leq F C)\end{array}= \begin{cases}0 & (0 \% \leq F C<10 \%) \\ (F C-10) / 18 & (10 \% \leq F C)\end{cases}\right.$

The $F_{L}$-value is evaluated usually at each $1 \mathrm{~m}$. The soil layers where $F_{L}$ is less than 1.0 is evaluated to be liquefiable under the design ground motion. When it is estimated that liquefaction occurs from Eqn. (19), both spring stiffness $k_{S L}$ and bearing capacity of soils $p_{S L}$ in liquefying layers are reduced from the original spring stiffness $k_{S}$ and bearing capacity $p_{S}$ as

$k_{S L}=c_{L} k_{S} ; p_{S L}=c_{L} p_{S}$

in which $c_{L}$ is soil parameter reduction factor associated with liquefaction, and is provided depending on $F_{L}$ value, depth and cyclic shear strength ratio $R$ as shown in Table 3 .

Table 3 Soil Parameter Reduction Factor Associated with Liquefaction $c_{L}$ in Eqn. (25)

\begin{tabular}{|c|c|c|c|}
\hline$F_{L}$-value & $\begin{array}{c}\text { Depth } \mathrm{x} \text { from } \\
\text { Ground Surface }(\mathrm{m})\end{array}$ & \multicolumn{2}{|c|}{ Cyclic Shear Strength Ratio $R$} \\
\cline { 2 - 4 } & $0 \leq \mathrm{x} \leq 10$ & 0.3 & $\mathrm{R}>0.3$ \\
\hline$F_{L} \leq 1 / 3$ & $10<\mathrm{x}<20$ & $1 / 3$ & $1 / 6$ \\
\hline \multirow{2}{*}{$1 / 3<F_{L} \leq 2 / 3$} & $0 \leq \mathrm{x} \leq 10$ & $1 / 3$ & $1 / 3$ \\
\cline { 2 - 4 } & $10<\mathrm{x}<20$ & $2 / 3$ & $2 / 3$ \\
\hline $2 / 3<F_{L} \leq 1$ & $0 \leq \mathrm{x} \leq 10$ & $2 / 3$ & $1 / 3$ \\
\cline { 2 - 4 } & $10<\mathrm{x}<20$ & 1.0 & 1.0 \\
\hline
\end{tabular}

Typical soil profile at the sites where bridges suffered damage due to the liquefaction-induced ground movement consisted of reclaimed top soil resting on loose sandy layers as shown in Figure 7. Liquefaction occurred in the loose sandy layers, while the top soil did not liquefy. The top soil however moved associated with the lateral movement of the loose sandy layers. It was often that footings were embedded in the top soil. Hence, a large lateral force applied to the footings from in the top soil. Although the mechanism of lateral ground movement is still under investigation, it was found in the $\mathrm{H}-\mathrm{k}-\mathrm{n}$ earthquake that it was triggered by failure of revetment along the shoreline, and thus the amount of ground movement reduced as the distance from the failed revetment 


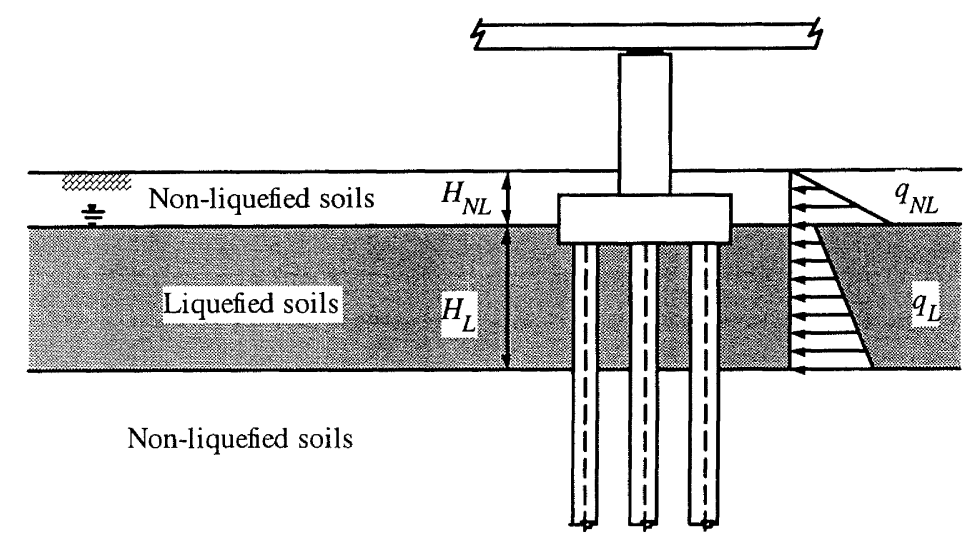

Figure 7 Treatment of Liquefaction-Induced Ground Movement

increased. It was also found that ground movements were larger when the sea bottom was deep from the ground surface.

When the ground movement occurs, force associated with the ground movement applies to a part of foundation in touch with the moving ground. To represent such force mechanism, it is appropriate to idealize the foundation to be a structure supported by soil springs, and prescribe the movement of ground at the end of each soil spring. In such an analytical mode, it is important how accurately amount of ground movement can be predicted. Since the evaluation of maximum ground movement was difficult, an analytical model in which the force associated with ground movement applies to the foundation was included in the 1996 Design Specifications [JRA 1996]. The foundation is idealized as a structure supported by soil springs. The reduction of soil springs based on Eqn. (25), if any, is accounted in the model. Then distributing forces apply to a part of the foundation in nonliquefying ground (top soil) and liquefying ground as shown in Figure 7. The distributing forces which apply to a part of the foundation in non-liquefying and liquefying soils, $q_{N L}(\mathrm{kN} / \mathrm{m})$ and $q_{L}(\mathrm{kN} / \mathrm{m})$, respectively, are provided as

$q_{N L}=c_{s} \cdot c_{N L} \cdot K_{P} \cdot \gamma_{N L} \cdot x \quad\left(0 \leq x \leq H_{N L}\right)$

$q_{L}=c_{s} \cdot c_{L} \cdot\left\{\gamma_{N L} \cdot H_{N L}+\gamma_{L} \cdot\left(x-H_{N L}\right)\right\} \quad\left(H_{N L} \leq x \leq H_{N L}+H_{L}\right)$

in which $K_{P}$ =passive earth-pressure coefficient, $\gamma_{N L}$ and $\gamma_{L}$ =unit weight of non-liquefying and liquefying soils, $H_{N L}$ and $H_{L}$ =thickness of non-liquefying and liquefying soils, $x=$ depth from the ground surface, $c_{s}=$ modification factor depending on distance from shoreline, and $c_{N L}$ and $c_{L}=$ modification factor for ground movement-induced force in non-liquefying and liquefying soils, respectively. Based on several back-analyses of bridges which suffered damage from the ground movement in the H-k-n earthquake and shaking table tests, the modification factor $c_{L}$ was recommended to be 0.3 [MOC 1995, Tamura and Azuma 1997, Tamura et al. 2000]. Based on the empirical evaluation of the damage in the H-k-n earthquake and a series of shaking table tests, $c_{s}=1.0,0.5$ and 0.0 corresponding to $s \leq 50 \mathrm{~m}, 50<s \leq 100 \mathrm{~m}$ and $199 \mathrm{~m}<s$, respectively, where $s$ is the distance from shoreline, and $c_{N L}=0.0,\left(0.2 P_{L}-1\right) / 3$ and 1.0 corresponding to $P_{L} \leq 5,5<P_{L} \leq 20$ and $20<P_{L}$, respectively, where the liquefaction index $P_{L}$ defined as

$P_{L}=\int_{0}^{20}\left(1-F_{L}\right)(10-0.5 x) d x$

\section{RECENT SEISMIC DESIGN CODES AND THEIR FEATURE}

\section{Seismic Design Codes}

As a consequence of recent earthquakes including the 1989 Loma Prieta, 1994 Northridge and 1995 Hyogo-ken nanbu earthquakes, seismic design codes for highway bridges have been revised. As described in the previous chapter, Design Specifications of Highway Bridges were fully revised in 1996 in Japan. In 1994, Part 2 Bridges in Eurocode 8 Design provisions for earthquake resistance of structures was proposed as the European Prestandard [Pinto 1995]. In New Zealand, the Transit New Zealand Bridge Manual was revised in 1995 [TNZ 1995, Chapman 1995]. In the United States, the American Association of Highway and Transportation Officials (AASHTO) published two codes for the design of highway bridges: Standard Specifications for Highway Bridges and LRFD Bridge Design Specifications. The Department of Transportation of the State of California 
(Caltrans) has developed an independent seismic design specifications which are similar to, but not the same as, the AASHTO provisions. ATC-32 recommendation was published to improve Caltrans seismic design practice [ATC 1996]. Caltrans recently developed the Seismic Design Methodology [Caltrans 1999a] and the Seismic Design Criteria [Caltrans 1999b].

In this chapter, recent progress in those seismic design codes for highway bridges is presented. Since different notations and acronyms in equations and tables are used in these codes, they are modified herein from the original definitions so that comparison between the codes can be made easier.

\section{Design Philosophy and Seismic Performance Criteria}

In seismic design of structures, it is important to have a clear vision on the seismic performance. Decision on "how do you want the structure to perform in an earthquake ?", "how much danger can you accept ?" and "what are the reasonable alternate routes ?" [Roberts 1999] is certainly important. The basic concept of design philosophy and seismic performance criteria is more or less similar among the codes, i.e., for small-to-moderate earthquakes bridges should be resisted within the elastic range of the structural components without significant damage, and bridges exposed to shaking from large earthquakes should not cause collapse [Buckle 1996].

In each code, the performance requirements depend on the importance of bridges. The importance is classified into 2-3 categories. In EC and New Zealand codes, design force is factored by the importance factor. In AASHTO and Caltrans, the importance is reflected in the evaluation of response modification factor. In Japan, the importance is reflected in the evaluation of allowable ductility factor of substructures, and this subsequently affects the evaluation of seismic modification factor.

The anticipated function of a bridge after a design earthquake depends on the codes. In New Zealand, the bridge must be usable by emergency traffic, although damage has occurred and some temporary repairs may be required. As usual, expression is moderate in the Japanese code as shown in Table 4(1). The performance criteria for important bridge are that the bridge should retain the "limited damage." It is presented in the commentary that the "limited damage" intends not to exceed the stage where the restoring force of piers initiates to deteriorate. Hence, the "limited damage" intends to be almost "immediately functional."

In the $1995 \mathrm{H}-\mathrm{k}-\mathrm{n}$ earthquake, even engineers in the organizations with jurisdiction to the construction and maintenance of bridges, such as Hanshin Expressway Public Corporation, suffered damage to their family and properties. Due to the lack of information, it was almost days after the earthquake when the approximate damage situation was identified based on the inspection from outside the structures. If damage occurred at only a bridge, temporary shoring of the structure was possible in a couple of days after the earthquake. However, since extensive damage occurred in a wide area, it was unable to conduct the temporary shoring for a number of bridges shortly after the earthquake. Stock of the structural members for replacement, such as bearings, expansion joints and cable restrainers, were not available. It took long time to fabricate them after order. For example, structural steel plates were not available for reconstruction of steel girders, hence the structural steel plates which were ordered prior to the earthquake by other organization for construction of steel bridges at other locations were used for the reconstruction of steel girders in the damaged area. Based on such experience, it was obvious that bridges in important routes should not suffer damage to the extent that requires repairing immediately after an earthquake. If this occurred, repair within a month or even months of the earthquake is difficult. Prior to the H-k-n earthquake, there was an augment whether bridges should have higher seismic performance than buildings or not. It is now obvious that bridges in important routes should have higher seismic performance than buildings, because restoration due to collapse of buildings cannot be conducted if the bridges having the same seismic performance with the buildings suffer damage.

In the ATC-32 and the Caltrans code, the performance criteria is clearly stated as shown in Table 4(2) by classifying them into requirements in service level and damage level. In the service level, "immediate" implies full access to normal traffic almost immediately following the earthquake, and "limited" implies that limited access (reduced lanes, light emergency traffic) is possible within days of the earthquake, and that full service is restorable within months. In the damage level, "repairable damage" intends damage that can be repaired with a minimum risk of losing functionality. "Significant damage" intends a minimum risk of collapse, but that would require closure to repair, while "minimum damage" intends essentially elastic performance. "No collapse", "no major damage", "no secondary injuries or fatalities because emergency equipment cannot get through", "major important structures and lifeline routes must remain operational" are the current Caltrans performance criteria [Roberts 1999]. It is important that the important bridges should have full access to normal traffic immediately following the safety-evaluation earthquake. 
Table 4 Seismic Performance Criteria

(1) JRA (1996)

\begin{tabular}{|c|c|c|c|}
\hline \multicolumn{2}{|r|}{ Ground Motions } & Ordinary Bridges & Important Bridges \\
\hline GM wit & high probability of occurrence & Functional & Functional \\
\hline $\begin{array}{l}\text { GM with low probability } \\
\text { of occurrence }\end{array}$ & $\begin{array}{l}\text { Type I GM (Plate-boundary-type-earthquakes) } \\
\text { Type II GM (Intra-plate-type-earthquakes) }\end{array}$ & $\begin{array}{l}\text { Prevent critical } \\
\text { damage }\end{array}$ & $\begin{array}{l}\text { Retain limited } \\
\text { damage }\end{array}$ \\
\hline
\end{tabular}

(2) ATC32 and Caltrans (1999)

\begin{tabular}{|c|c|c|c|c|}
\hline \multirow{2}{*}{ Ground Motions } & \multicolumn{2}{|c|}{ Service level } & \multicolumn{2}{c|}{ Damage level } \\
\cline { 2 - 5 } & Ordinary Bridges & Important Bridges & Ordinary Bridges & Important Bridges \\
\hline Functional-Evaluation GM & Immediate & Immediate & Repairable Damage & Minimum Damage \\
\hline Safety-Evaluation GM & Limited & Immediate & Significant Damage & Repairable Damage \\
\hline
\end{tabular}

\section{Seismic Loads}

All the codes listed above except New Zealand represent the design force by $5 \%$ damped elastic response spectra. In EC code, the elastic response acceleration $S$ for the reference return period is defined depending on the local soil condition as

$$
S=k_{I} \cdot k_{G C} \cdot a_{g} \cdot \begin{cases}1+\frac{T}{T_{B}}\left(k_{D} \beta_{0}-1\right) & 0 \leq T \leq T_{B} \\ k_{D} \cdot \beta_{0} & T_{B} \leq T \leq T_{C} \\ k_{D} \cdot \beta_{0} \cdot\left(\frac{T_{C}}{T}\right) & T_{C} \leq T \leq 3 s \\ k_{D} \cdot \beta_{0} \cdot\left(\frac{T_{C}}{3}\right) \cdot\left(\frac{3}{T}\right)^{2} & 3 s \leq T\end{cases}
$$

in which $k_{I}$ =importance factor $(1.0,1.3$ and 0.7 for average, greater than average and less than average importance bridges, respectively), $k_{G C}=$ ground condition factor ( 1.0 for $\mathrm{A}+\mathrm{B}$, and 0.9 for $\mathrm{C}$ subsoil conditions), $k_{D}=$ damping modification factor, $\beta_{0}=$ spectral acceleration amplification factor $(=2.5), a_{g}=$ design ground acceleration $(g)$, and $T_{B}$ and $T_{C}=$ limits of the constant spectral acceleration branch $\left(T_{B}=0.1,0.15\right.$ and 0.2 seconds in subsoil class A, B and C, and $T_{C}=0.4,0.6$ and 0.8 seconds for subsoil class $\mathrm{A}, \mathrm{B}$ and $\mathrm{C}$, respectively). The damping modification factor $k_{D}$ in Eq. (29) is given in terms of damping ratio $\xi$ as

$k_{D}=\sqrt{0.07 /(0.02+\xi)} \geq 0.7$

The design seismic force for averaged-importance bridges $\left(k_{I}=1.0\right)$ usually reflects a design seismic event with a return period of approximately 475 year. Such an event has a probability of exceedance ranging from 0.1 to 0.19 for a design life time ranging from 50 to 100 years, respectively.

In New Zealand, the horizontal seismic force for the equivalent static analysis is provided with the inelastic response spectra $S_{i}$ as

$S_{i}=k_{Z} \cdot k_{I} \cdot k_{G C} \cdot S_{\mu}(T)$

in which $k_{Z}=$ zone factor (0.6-1.2 depending on zones), $k_{I}=$ importance factor (risk factor; $1.3,1.15$ and 1.0 for bridges with importance category of 1,2 and 3 , respectively), $k_{G C}=$ ground condition factor (structural performance factor; $0.9,0.8$ and 0.67 for rocky or very stiff soil sites, intermediate soil sites, and flexible or deep soil sites, respectively), and $S_{\mu}(T)=$ basic acceleration coefficient multiplied by gravity acceleration $\mathrm{g}$, and is give in figures. Factoring by $k_{I}$, the return period of design earthquakes is about 900 and 650 years for bridges with the important factor of 1.3 and 1.15 , respectively.

In the AASHTO, the response acceleration spectrum $S$ is given as

$S=\frac{1.2 \cdot a_{g} \cdot k_{G C}}{T^{2 / 3}} \leq 2.5 a_{g}$

in which $a_{g}=$ ground acceleration $(g)$, and $k_{G C}=$ site modification factor $(1.0,1.2,1.5$ and 2.0 for ground condition I, II, III and IV, respectively). $a_{g}$ is provided as contour for return period of 475 year. The highest value of $a_{g}$ throughout the US is $>0.8 \mathrm{~g}$ in a part of Alaska and California. Maximum probable earthquake with a return period of around 2,500 years has to be further considered. 
On the other hand, in the ATC-32 and Caltrans [1999], the new response accelerations for the safety-evaluation have been used to represent the near-field ground motions. They are assessed either deterministically or probabilistically. The deterministic evaluation corresponds to the maximum credible earthquake, while the probabilistically assessed ground motion is one with approximately 1,000-2,000 year return period. The response acceleration $S$ (ARS response curves) is provided in figures depending on peak ground acceleration $a_{g}(0.1$ $0.7 \mathrm{~g}$ ), site condition (soil profile Type B-E), and earthquake magnitude $(6.5 \pm 0.25,7.25 \pm 0.25$, and $8.0 \pm 0.25)$. The peak ground acceleration $a_{g}$ is evaluated by CDMG based on a deterministic procedure for maximum credible earthquakes.

To take account of the near-field ground motion effect for bridges within $15 \mathrm{~km}$ from an active fault, Caltrans magnifies the response acceleration $S$ by $20 \%$ for natural period $T \geq 1.0$ seconds, and a value determined by linear interpolation for $0.5 \leq T \leq 1.0$ seconds. The response acceleration is not magnified for $T<0.5$ seconds. Furthermore, to take account of amplification in soft soil deposits, for bridges with natural period equal to or larger than 0.5 seconds constructed on deep soil sites (depth of alluvium soils over $75 \mathrm{~m}$ ), Caltrans also magnifies the response acceleration $S$ by $20 \%$ for $T \geq 1.5$ seconds, and the value determined by linear interpolation for $0.5 \leq T \leq 1.5$ seconds. The response acceleration is not magnified for $T \leq 0.5$ seconds.

A comparison of design linear response acceleration between EC-8, New Zealand, Japan and US was conducted under the following assumptions;

- Compare the largest linear response acceleration of 5\% damping ratio corresponding to the largest factors and design accelerations, if available.

- Assume that three ground condition category in EC-8, New Zealand and Japan are close each other. They are called herein "stiff," "moderate," and "soft." Assume also that the soil profile Type-II, III and IV in AASHTO and the soil profile C, D and E in Caltrans correspond to the stiff, moderate and soft soil category.

- In EC-8, assume $k_{I}=1.3$ and $a_{g}=0.7 \mathrm{~g}$ in Eqn. (29). It should be noted that $a_{g}=0.7 \mathrm{~g}$ may not be used in European countries, but this was assumed here for comparison. In New Zealand code, assume $k_{Z}=1.2$, $k_{I}=1.3$ and $\mu=1$ in Eqn. (31). In the Japanese code, assume $k_{Z}=1.0$ in Eqs. (1) and (3). In AASHTO, assume $a_{g}=0.8 \mathrm{~g}$ in Eqn. (32). In Caltrans, consider two magnitude ranges; $7.25 \pm 0.25$ and $8.0 \pm 0.25$, and assume $a_{g}=0.7 \mathrm{~g}$ for stiff and moderate sites and $a_{g}=0.4 \mathrm{~g}$ for soft soil sites.

Figure 8 shows the comparison among the design accelerations in 4 codes. At stiff sites, the general trend of the response accelerations are similar among the codes, except the Type-I ground motion in Japan provides smaller value. At soft soil sites, EC-8 and AASHTO provide larger response accelerations at the constant response acceleration range. The Caltrans, New Zealand and Japan codes provide the similar response. The difference between $M=7.25 \pm 0.25$ and $8.0 \pm 0.25$ is small in the Caltrans. It should be noted that this comparison reflects the assumptions described above.

\section{Analytical Methods and Design Requirements}

In the ATC-32, the analytical methods are classified into "Elastic Static Analysis" (ESA), "Elastic Dynamic Analysis" (EDA), "Inelastic Static Analysis" (ISA), and "Inelastic Dynamic Analysis" (INA). In ESA, the elastic response of a bridge is divided by the response modification factor, and the structural components are 


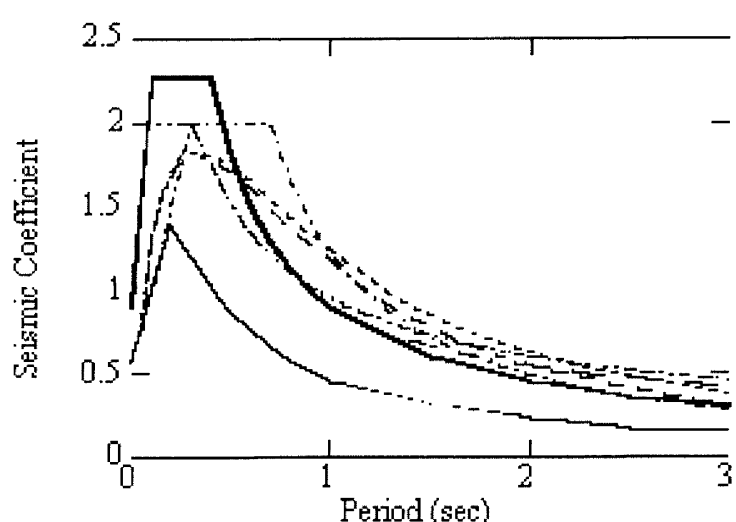

(a) Stiff Soil Site

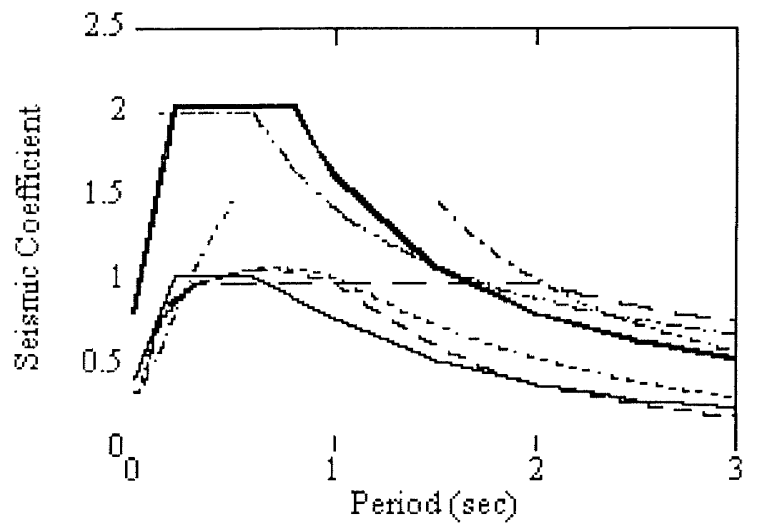

(c) Soft Soil Site

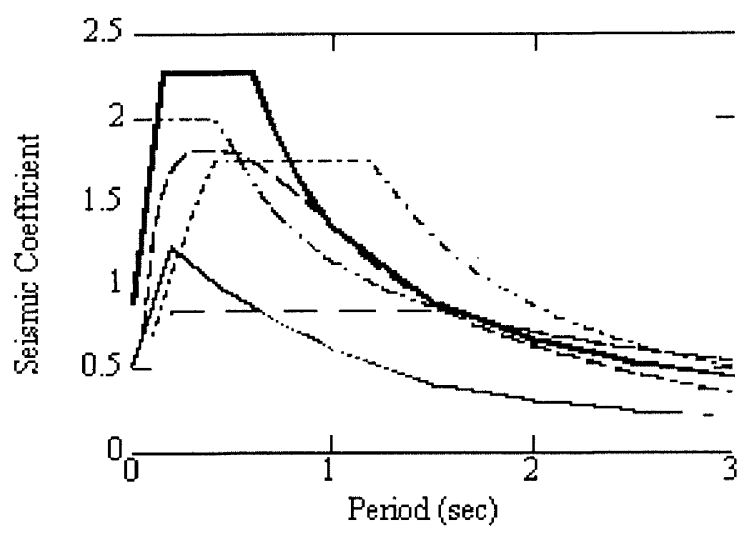

(b) Moderate Soil Site

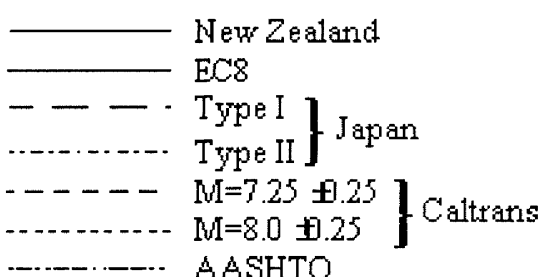

Figure 8 Comparison of Linear Response Accelerations of 5\% Damping Ratio among EC-8, New Zealand, Japan and US codes

sized based on the capacity design approach. On the other hand, push-over analysis is used in ISA. The minimum analysis requirements are presented in Table 5. The requirements vary with bridge category, configuration type and evaluation level. Configuration Type-I is intended to include bridges with simple response characteristics, including bridges with continuous superstructure, well-balanced spans, supporting bents with appropriately equal stiffness and insignificant vertical response. Configuration Type-II is intended to include bridges with more complex response characteristics that are unlikely to be represented well by ESA, including bridges with intermediate superstructure hinges, irregular configuration, bents of nonuniform stiffness, significant skew or spans likely to be excited by vertical input motion.

Table 5 Minimum Required Analysis (ATC-32, 1996)

\begin{tabular}{|c|c|c|c|}
\hline Importance & Configuration & Functional Evaluation & Safety Evaluation \\
\hline Ordinary & Type-I & None required & ESA or EDA \\
\cline { 2 - 4 } Bridge & Type-II & None required & EDA \\
\hline Important & Type-I & ESA or EDA & ESA or EDA \\
\cline { 2 - 4 } Bridge & Type-II & EDA & EDA, ISA and IDA \\
\hline
\end{tabular}

If one follows the classification in Table 5, EDA and ESA are used in EC-8. Detailed description is provided for three methods in ESA; the rigid deck mode, flexible deck model and individual pier model. They are selected depending on the relative deformation of deck and the interrelation of response of adjacent piers. In New Zealand, ESA, EDA and IDA are used. Dynamic analysis (EDA and IDA) is recommended when it is not appropriate to represent the bridge as a single-degree-of-freedom oscillator. In Japan, analytical methods are also chosen depending on the structural configuration as shown in Table 6. Push over analysis is used for almost bridges, in particular for design of moment-resisting frame piers and foundations. Inelastic dynamic response analysis is widely adopted on routine basis. Since the input data required for push-over analysis and EDA are almost the same with IDA, IDA is easily conducted once the data are prepared. Based on the advance of personal computers, movement toward more frequent use of IDA may be accelerated in the future. In Caltrans, ESA, EDA and ISA are used. 
Table 6 Minimum Required Analysis (JRA, 1999)

\begin{tabular}{|c|c|c|c|}
\hline \multicolumn{2}{|c|}{ Category } & Functional Evaluation & Safety Evaluation \\
\hline \multicolumn{2}{|c|}{ Bridges with Simple Response Characteristics } & ESA & ISA \\
\hline Bridges with Complex & Equivalent Static Analysis is Applicable & ESA and EDA & ISA and IDA \\
\cline { 2 - 4 } Response Characteristics & Equivalent Static Analysis is not Applicable & EDA & IDA \\
\hline
\end{tabular}

\section{Response Modification Factor and Target Displacement Ductility Demand}

In ESA, response modification factor is important in evaluating the demand. In EC-8, it is intended that bridges behave under the design seismic action in ductile or limited ductile/essentially elastic. In ductile behavior, the response modification factor (behavior factor $q$ ) is 1.0-3.5, 2.0-3.5, 1.0 and 2.0 for reinforced concrete piers, steel piers, abutments and arches, respectively.

In Japanese Design Specifications, the values of response modification factor are not presented, because they are computed each by each by Eqn. (15) based on the equal energy principle using the allowable displacement ductility factor of piers. However, since the allowable displacement ductility should be equal or less than 8 , the response modification factor is equal to or smaller than $\sqrt{2 \times 8-1}=3.87$. Since the allowable displacement ductility factor is generally in the range of 4-6 in ordinary reinforced concrete single piers, the response modification factor is 2.6-3.3.

In New Zealand, response modification factors are not required because nonlinear response accelerations are provided in Eq. (31). Hence, the maximum allowable displacement ductility factor is provided depending on the hysteretic structural behavior and accessibility to the damaged portion. For example, in the ductile or partially ductile structures (Type-I), the maximum allowable displacement ductility factor is 6 when plastic hinges form above the ground or normal water level. But it must be 4 when the plastic hinges form in reasonably accessible position (e.g., less than $2 \mathrm{~m}$ below ground surface), and 3 when they form at inaccessible position (e.g., more than $2 \mathrm{~m}$ below ground surface).

In AASHTO, the response modification factors are provided depending on the type of piers and the importance. They are 1.5, 1.5-3.5, and 2.0-5.0 in critical, essential, and other bridges, respectively. For single columns, it is $1.5,2.0$ and 3.0 in critical, essential and other bridges, respectively. Special interest is the response modification factor for connections. It is 0.8 for superstructure to abutment connection.

In Caltrans, the allowable maximum displacement ductility factor is provided. It is 5 for multi-column bents, 4 for single column bents, and 5 and 1 for pier walls in weak and strong direction, respectively. Quantitative definition of the damage corresponding to different performance requirements has not yet been specified in the Version 1.0 Caltrans-SDC. Table 7 provides a quantitative strain and ductility limit corresponding to the three damage levels [Duan and Chen 1999].

Table 7 Damage Levels, Strain and Ductility [Duan and Chen 1999]

\begin{tabular}{|c|c|c|c|c|}
\hline \multirow{2}{*}{$\begin{array}{c}\text { Damage } \\
\text { Level }\end{array}$} & Concrete & Strain & Curvature $\mu_{\phi}$ & Displacement $\mu_{d}$ \\
\cline { 2 - 5 } & $\varepsilon_{c u}$ & $\varepsilon_{s h}$ & $8-10$ & $4-6$ \\
\hline Significant & larger between 0.005 and $2 \varepsilon_{c u} / 3$ & larger between 0.08 and $2 \varepsilon_{y} / 3$ & $4-6$ & $2-4$ \\
\hline Repairable & larger between 0.004 and $\varepsilon_{c u}$ & larger between 0.03 and $1.5 \varepsilon_{y}$ & $2-4$ & $1-2$ \\
\hline Minimum & layy \\
\hline
\end{tabular}

\section{SEISMIC RETROFIT}

\section{Steel Jacket for Retrofit of Reinforced Concrete Piers}

Extensive seismic retrofit of reinforced concrete piers has been conducted in California and Japan. Target of the retrofit is to prevent premature shear failure in the piers designed according to the pre-1971 design in California and the pre-1980 design in Japan. After the H-k-n earthquake, 29,400 piers were retrofitted in Japan.

In addition to the increase of shear strength, slight increase of flexural strength is intended in Japan. This is because there is some redundancy in the strength of foundations. Based on background analyses, it was found that if the increasing rate of flexural strength of piers is less than 1.7, this does not result in serious failure in the 
foundations. The increase of flexural strength contributes to decrease the residual displacement of the piers after a design earthquake. Hence steel jacket as shown in Figure 9 has been used as a standard retrofit method for single reinforced concrete piers that were designed according to the pre-1980 Design Specifications. To increase the flexural strength in a controlled manner, anchor bolts were provided at the bottom of steel jacket. By appropriately choosing the number and size of the anchor bolts, the increase rate of flexural strength can be controlled. The thickness of jacket was recommended to be $9 \mathrm{~mm}$ and $12 \mathrm{~mm}$ (SS400) for piers with section width (transverse direction) and section height (longitudinal direction) ratio $a / b$ less than or equal $2 \mathrm{and} a / b$ over 2 , respectively. For piers with larger $\mathrm{a} / \mathrm{b}$ ratio, cross bars were recommended. In evaluating the confinement effect, the steel jacket was accounted in the tie reinforcement ratio $\rho_{s}$ in Eqn. (8). Non-shrinkage mortar or epoxy resin was injected between the steel jacket and concrete pier. For anchor bolts, D35 bars (SD295) were recommended in each $250 \mathrm{~mm}$ spacing.

In Japan, rectangular piers are more often adopted than circular piers. Confinement by steel jacket is not enough for rectangular piers with larger sections. Although change of the rectangular shape to elliptical shape has been successfully conducted in USA [Priestley 1996, Roberts 1999], it was in most cases difficult in urban freeways
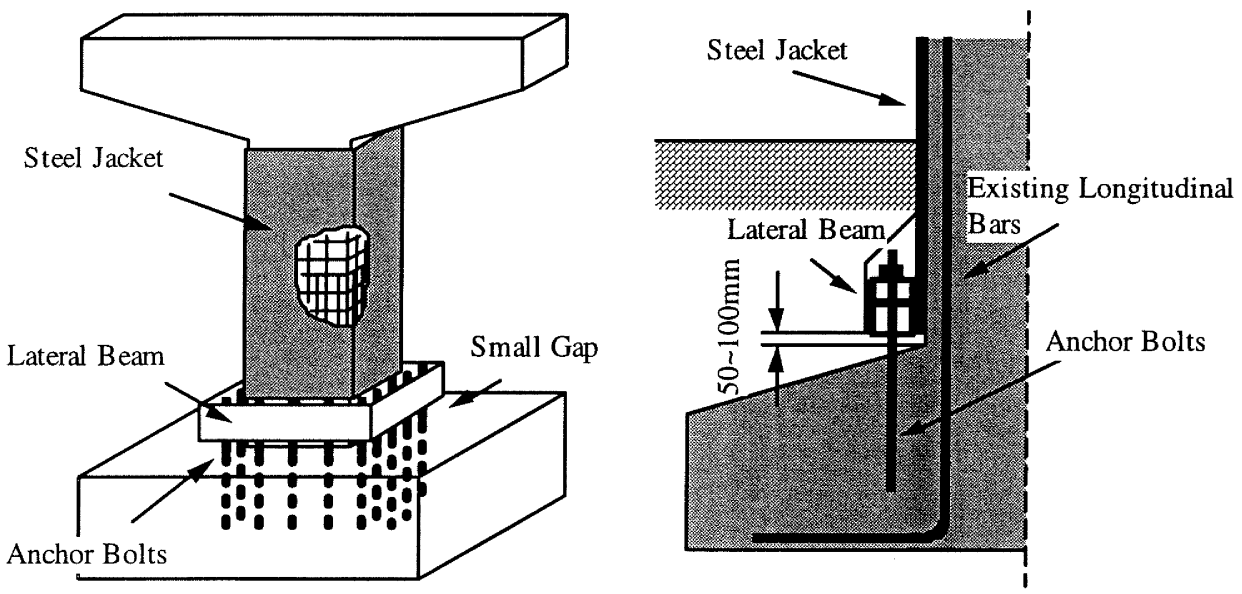

Figure 9 Steel Jacketing with Controlled Increase of Flexural Strength

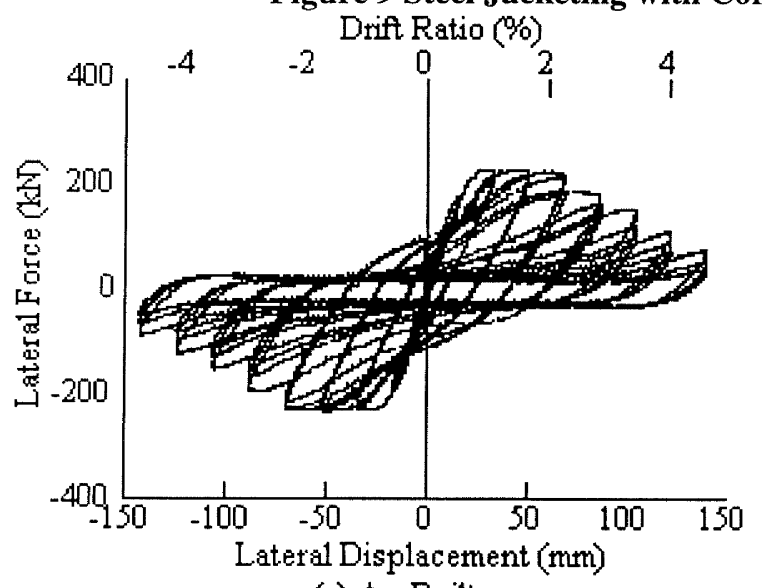

(a) As-Built

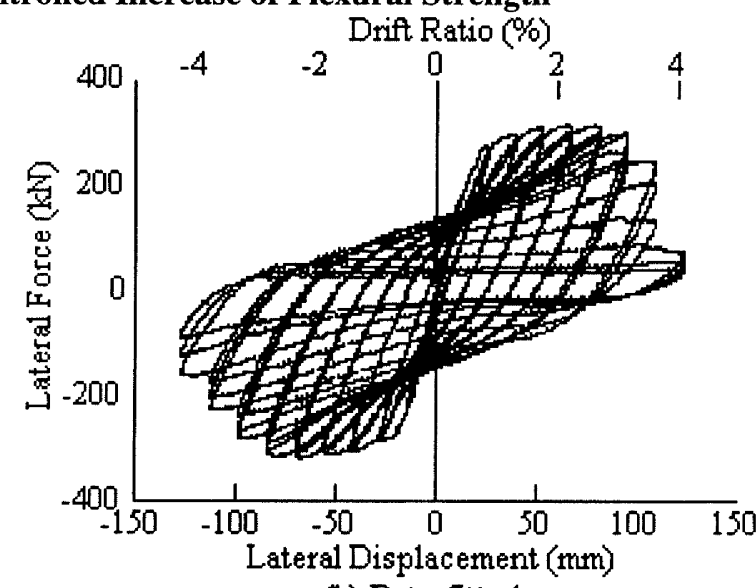

(b) Retrofitted

Figure 10 Effect of Steel Jacket with Controlled Increase of Flexural Strength for Rectangular Piers 


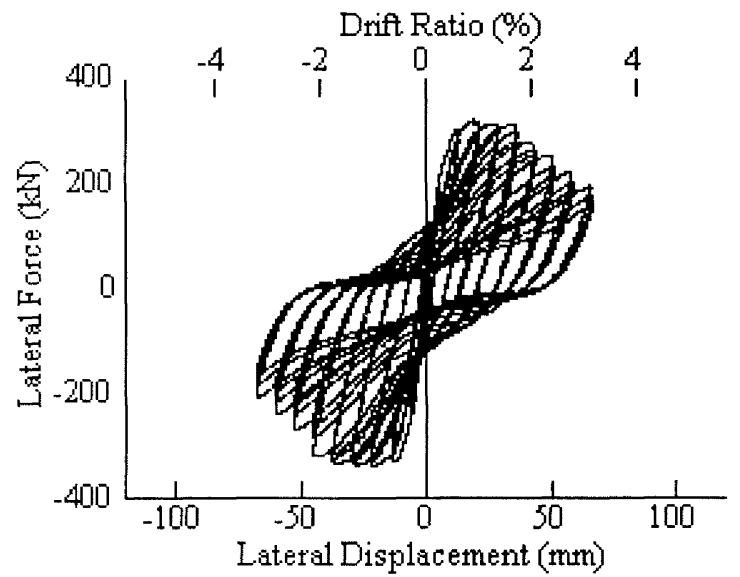

(a) As-Built.

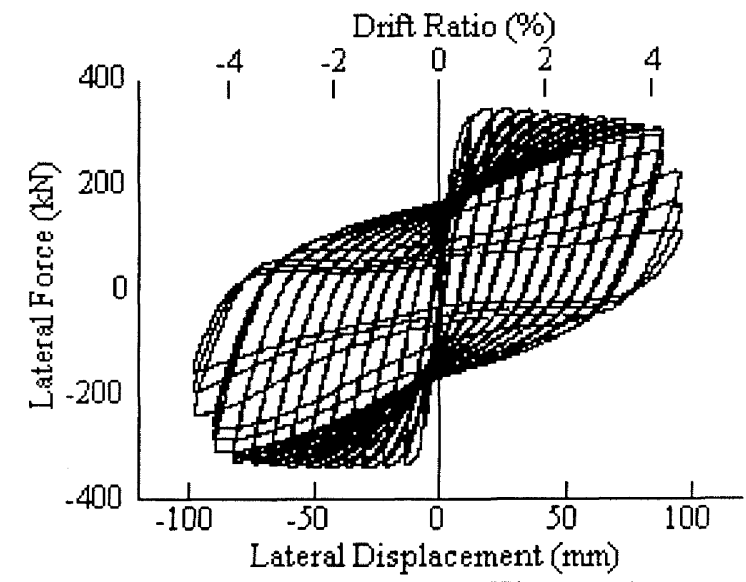

(b) Retrofitted (Horizontal Wrapping)

Figure 11 Effect of Carbon Fiber Sheets Jacketing for Circular Piers [Hoshikuma et al. 1996, Unjoh et al. 1997]

in Japan due to limitation of space. Thus, a lateral beam ring (H-shape beam) was provided at the bottom of steel jacket. Since it was anxious about the number of beam rings required at the plastic hinge region, a cyclic loading test was conducted. It showed that a bottom beam ring is sufficient to increase ductility. A small gap was provided between the bottom of steel jacket and the top of footing [Priestley et al. 1996]. Figure 10 shows the effect of steel jacket for $3.01 \mathrm{~m}$ high rectangular piers with a section of $600 \mathrm{~mm} \times 600 \mathrm{~mm}$ [Hoshikuma et al. 1996, Unjoh et al. 1997]. Flexural strength and displacement ductility factor of the retrofitted pier increased by a factor of 1.39 and 1.4 from as-built pier, respectively.

\section{Composite-Materials Jackets}

Composite-materials such as high-strength fiberglass jackets, aramid-fiber-reinforced-plastics jackets, and carbon-fiber-sheet (CFS) jackets have been investigated [e.g., Ogata et al. 1994, Priestley et al. 1996]. They have been used at the piers where enough construction space was not available. The aramid-fiber-reinforced-plastics jackets and carbon-fiber-sheet jackets have been adopted in seismic retrofit of railway bridges in Japan [Wakui et al. 1997, JTRI 1997]. Since the section sizes of railway bridges are generally smaller, the new techniques have been implemented after they were confirmed based on cyclic loading tests.

Figure 11 shows the effect of CFS jackets for $2.1 \mathrm{~m}$ high circular piers with a diameter of $700 \mathrm{~mm}$ [Unjoh et al. 1997]. CFS was wrapped in two ways; horizontal direction alone and horizontal + vertical directions. The vertical CFS was wrapped to slightly increase the flexural strength, and was fixed to the footing thorough steel plates. The horizontal and horizontal + vertical wrapping of CFS increased the drift ratio to $200 \%$ and $300 \%$, respectively.

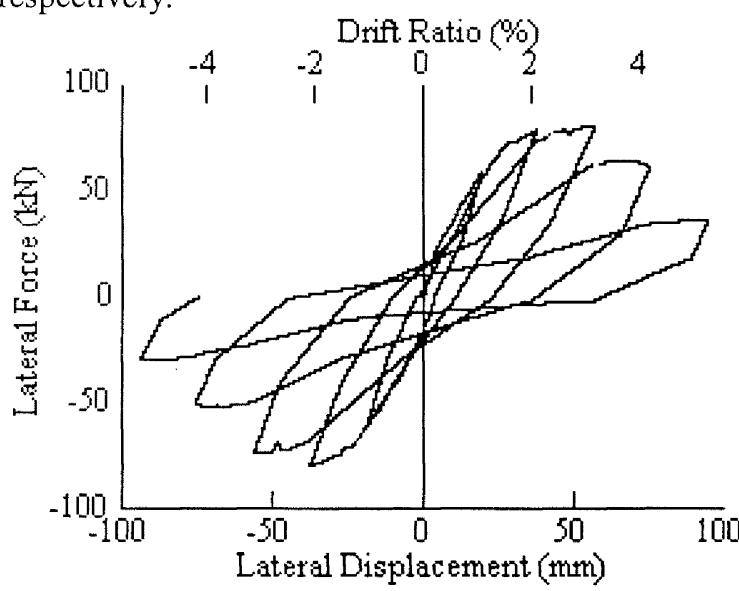

(a) As-Built

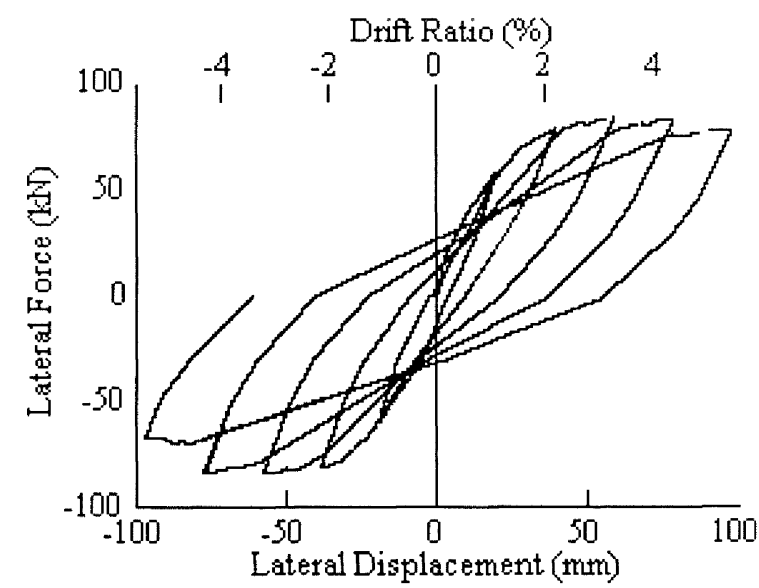

(b) Retrofitted

Figure 12 Effect of Carbon Fiber Sheet Jacketing for Piers in Sakawa-gawa Bridge [Ogata et al. 1999, Osada et al. 1999] 


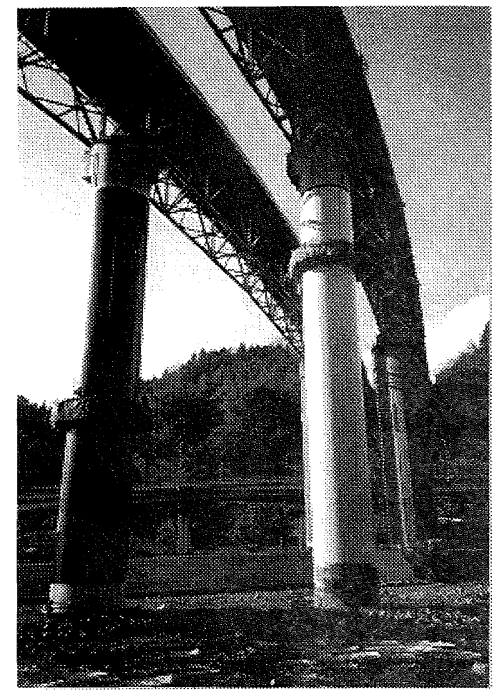

(a) Retrofitted East- and West-Bound Bridge

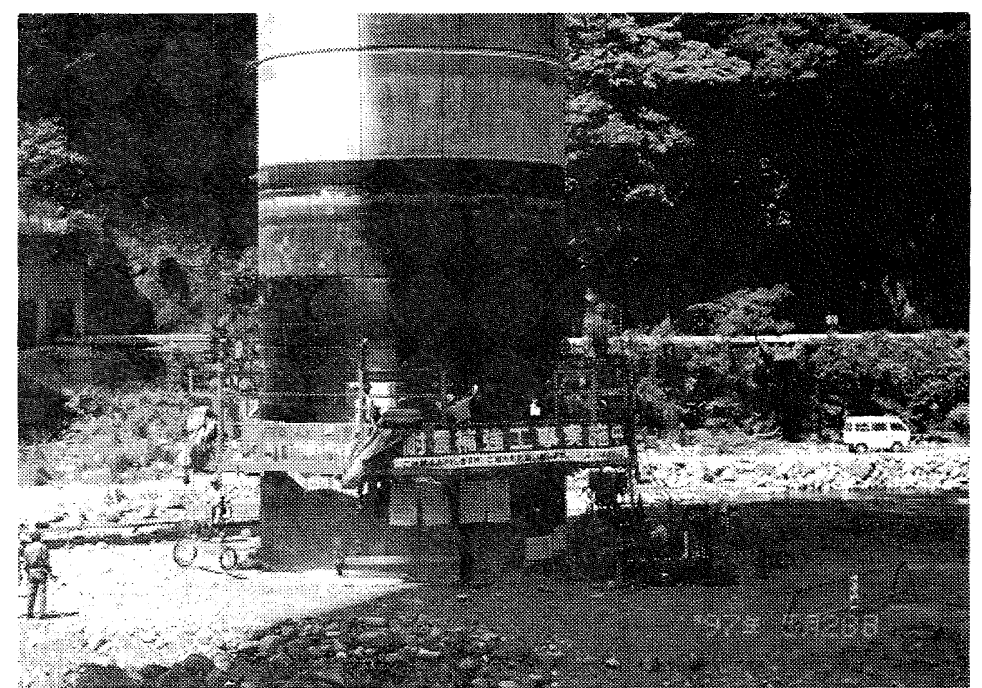

(b) Wrapping of Carbon Fiber Sheets

Photo 1 Carbon Fiber Sheet Jacketing of Hollow Reinforced Concrete Piers, Sakawa-gawa Bridge, Tomei Expressway, Japan Highway Public Corporation [Ogata et al. 1999, Osada et al. 1999]

One of the most extensive seismic retrofits of highway bridges using the CFS was conducted at the Sakawagawa Bridge, Tomei-Expressway, Japan Highway Public Corporation. The bridge is of 5-span continuos steel girder supported by 5(number) $42-65 \mathrm{~m}$ high hollow reinforced concrete piers. They were designed according to the 1964 Design Specifications. Before the retrofit, a series of cyclic loading tests were conducted [Ogata et al. 1997, Osada et al. 1999]. Figure 12 shows the effect of retrofit. Stable flexural capacity range increased from about $3 \%$ drift (as-built) to over 5\% drift (retrofitted). The seismic retrofit by CFS was implemented as shown in Photo 1. Wrapping was completed at the right piers and surface treatment was completed at the left piers.

Recently the Design Manual for Seismic Retrofit of Single Reinforced Concrete Piers by Carbon Fiber Sheets was published for reinforced concrete piers with diameter less than $3 \mathrm{~m}$ [CERI 1999]. It aims to prevent shear failure of both circular and rectangular piers, to enhance deformation capacity of circular piers, and to prevent premature flexure-shear failure of both circular and rectangular piers at midheight as a consequence of inadequate termination of longitudinal reinforcements. For preventing the flexure-shear failure at midheight, it is required to wrap CFS in not only horizontal direction but also vertical direction.

\section{CONCLUDING REMAREKS}

In the 1994 Northridge and the 1995 H-k-n earthquakes, the bridges designed in accordance with the pre-1971 and the pre-1980 design methods suffered extensive damage. Extensive progress has been achieved in the last two-three decades from the design based on old-concept that included too much simplifications and assumptions to the design based on new-concept based on the capacity design approach. Progress of computer analysis and experimental verification has been contributed to accumulate scientific knowledge on the inelastic response of bridges. Recent progress on theoretical estimation of near-field ground motions and verifications of design analysis by large-scale testing [e.g. Seible 1999] will further improve seismic design methods. However many problems have been left unsolved studied for inelastic response of bridges with multi plastic hinges, seismic performance of bridges under destructive near-field ground motions with long duration, pounding effect between decks, and seismic stability under liquefaction-induced lateral ground movement.

\section{ACKNOWLEDGEMENTS}

The author expresses his sincere appreciation for providing valuable information and material for this paper. Special appreciation is extended to Yashinsky, M. and Duann, L. (Caltrans), Wen, P. (FHWA), Osada, K. 
(JHPC), Irikura, K. and Kamae, K. (Kyoto University), Tamura, K., Unjho, S., Hoshikuma, J., and Nagaya, K. (PWRI), Ikeda, S. (Yokohama National University), and Kirkcaldie, D. (Works Consultancy Services).

\section{REFERENCE}

AASHTO (1995), Standard Specifications for Highway Bridges, 16th Edition, American Association of State Highway and Transportation Officials, USA

ATC (1996), Improved Seismic Design Criteria for California Bridges: Provisional Recommendations, ATC 32 , Applied Tech. Council, Redwood City, CA, USA

Buckle, I. A. (1996), "Overview of Seismic Design Methods for Bridges in Different Countries and Future Directions," Paper No. 2113, 11 WCEE, Acapulco, Mexico.

California Department of Transportation (1995), Bridge Design Specifications, Sacramento, CA, USA

California Department of Transportation (1999a), Bridge Memo to Designers (20-1)-Seismic Design Methodology, Sacramento, CA, USA

California Department of Transportation (1999b), Seismic Design Criteria, Ver. 1.1, Sacramento, CA, USA

Chapman, H. E. (1995), Earthquake Resistant Bridges and Associated Highway Structures: Current New Zealand Practice, Proc. National Seismic Conf. on Bridges and Highways, San Diego, CA, USA

Duann, L. and Chen, W.F. (1999), "Seismic Design Methodologies and Performance-Based Criteria," Proc. Int. Workshop on Mitigation of Seismic Effects on Transportation Struct. (Loh, C. H. et al editors), 130-141, National Center for Res. on Earthqu. Eng., Taipei, Taiwan, R.O.C.

European Prestandard (1994), Eurocode 8 - Design Provisions for Earthquake Resistance of Structures, Brussels.

Hartzell, S. H. (1978), “Earthquake Aftershocks as Green's function,” Geo-phys. Res. Lett. 22, pp101-104

Hamada, M., Isoyama, R. and Wakamatsu, K. (1995), The 1995 Hyogo-ken Nanbu Earthquake, Liquefaction, Ground Displacement and Soil Condition in Hanshin Area, Assn. for Development of Earthqu. Prediction.

Hoshikuma, J., Kawashima, K., Nagaya, K. and Taylor, A. W. (1997), "Stress-Strain Model for Confined Reinforced Concrete in Bridge Piers," J. Struct. Eng., ASCE, 123(5), pp624-633, NY, USA

Hoshikuma, J., Otsuka, H. and Nagaya (1996), "Seismic Retrofit of Square RC Columns by Steel Jacketing", Proc. 3rd U.S.-Japan Workshop on Seismic Retrofit of Bridges, pp 125-140

Irikura, K. and Kamae, K. (1999), "Strong Ground Motions during the 1948 Fukui earthquake-Estimation of Broad-band Ground Motion using a Hybrid Simulation Technique-," Jisin, 52, pp129-150, Tokyo, Japan

Railway Technical Research Institute (1997), Guide Specifications for Design and Construction of Seismic Retrofit of Railway Bridges by Aramid Fiber Reinforced Concrete Plastics, Kunitachi, Japan

Japan Road Association (1964), Design of Steel Bridges, Tokyo, Japan

Japan Road Association (1980), (1990), (1996), Design Specifications of Highway Bridges, Tokyo, Japan

Kamae, K. and Irikura, K. (1998), "Source Model of the 1995 Hyogo-ken Nanbu Earthquake and Simulation of Near-source Ground Motion,” BSSA, 88(2), pp400-412.

Kamae, K., Irikura, K. and Pitarka (1998), "A Technique for Simulating Strong Ground Motion using Hybrid Green's Function,” BSSA, 88(2), pp357-367

Kawashima, K., Aizawa, K. and Takahashi, K. (1984), "Attenuation of Peak Ground Motions and Absolute Acceleration Response Spectra", Proc. 8WCEE, pp257-264, Vol. II, San Francisco, CA, USA

Kawashima, K. and Aizawa, K. (1986), "Modification of Earthquake Response Spectra with Respect to Damping Ratio", 3rd US National Conf. Earthq. Eng., Charleston, SC, USA

Kawashima, K., Unjoh, S. and Mukai, H. (1994), Seismic Strengthening of Highway Bridges," 2nd US-Japan Workshop on Seismic Retrofit of Bridges, pp1-36, Report No. UCB/EERC 97-9, EERC, UCB, CA, USA

Kawashima, K. (1994), "Seismic Design Force of Bridges," Proc. 2nd Int. Workshop on Seismic Design and Retrofitting of Reinforced Concrete Bridges (Edited by Park, R.), Queenstown, NZ, pp25-56

Kawashima, K. (1997), "The 1996 Japanese Seismic Design Specifications of Highway Bridges and the Performance Based Design," Proc. Int. Workshop on Seismic Design Methodologies for the Next Generation of Codes (Fajfar, P. and Krawinkler, H. editors), Balkema, A. A., Rotterdam

Kawashima, K. and Unjoh, S. (1997), "The Damage of Highway Bridges in the 1995 Hyogo-ken Nanbu Earthquake and Its Impact on Japanese Seismic Design,” J. Earthq. Eng., 1(3), 505-541, IC Press, London, UK.

Kawashima, K., MacRae, G. A., Hoshikuma, J. and Nagaya, K. (1998), "Residual Displacement Response Spectrum," J. Struct. Eng., ASCE, 124-5, pp523-530, NY, USA

Kuribayashi, E. and Iwasakli, T. (1972), "Dynamic Properties of Highway Bridges," Proc. 5WCEE, Roma, Italy

Mahin, S. and Hachem, M. (1999), "Bi-directional Seismic Response of Reinforced Concrete Bridges," Proc. Int. Workshop on Mitigation of Seismic Effects on Transp. Struct. (Loh, C. H. et al. editors), 13-24, Nat. Center for Res. on Earthq. Eng., Taipei, Taiwan, R.O.C.

Ministry of Construction (1997), "Report on the Damage of Highway Bridges in the 1995 Hyogo-ken Nanbu Earthquake," Tokyo, Japan 
Narita, N., Murakami, M. and Asanuma, H. (1983), "Earthquake Damage to Shizunai Bridge," 15th Joint Meeting, US-Japan Panel on Wind and Seismic Effects, UJNR, Tsukuba Japan

Ogata, N, Maeda, Y and Ando, H. (1994), "Carbon Fiber Strengthening of Existing Bridges," 2nd US-Japan Workshop on Seismic Retrofit of Bridges, pp321-333, Report No. UCB/EERC 97-9, EERC, UCB, CA, USA

Ogata, T. and Osada, K. (1999), "Seismic Retrofitting of Expressway Bridges," Cement and Concrete Composites, 19, pp185-192, UK.

Osada, K., Yamaguchi, T. and Ikeda, S. (1999), "Seismic Performance and the Strengthening of Hollow Circular RC Piers Having Reinforced Cut-off Planes and Variable Wall Thickness," Concrete Res. and Tech., 10-1, pp. 13-24, Tokyo, Japan

Park, R. and Chapman, H. E. (1991), "Basic Design Concepts,” Proc. Int. Workshop on Seismic Design and Retrofitting of Reinforced Concrete Bridges (Calvi, G. M. and Priestley M. J. N. Editors), Bormio, Italy.

Park, R. (1996a), "New Zealand Perspectives on Seismic Design of Bridges," Paper No. 2111, 11WCEE, Acapulco, Mexico.

Pinto, P. E. (1995), "Eurocode 8 Part 2: Earthquake Resistant Design of Bridges," Proc. 1st Japan-Italy Workshop on Seismic Design of Bridges, 72-84, Tech. Memorandum, 3369, Public Works Res. Inst., ISSN 0386-5878, Ministry of Const., Tsukuba Science City, Japan.

Priestley, N. M. J. and Park, R. (1987), "Strength and Ductility of Concrete Bridge Columns under Seismic Loading," ACI Structural J. pp61-76.

Priestley, M. J. N., Seible, F. and Calvi, G. M. (1996), Seismic Design and Retrofit of Bridges, John Wiley \& Sons, New York, USA

Roberets, J. E. (1999), "Optimizing Post Earthquake Lifeline System Reliability - Seismic Design Details for Bridges," Proc. Int. Workshop on Mitigation of Seismic Effects on Transportation Struct. (Loh, C. H. et al editors), 282-293, Nat. Center for Res. on Earthq. Eng., Taipei, Taiwan, R.O.C

Sato, T. (1997), "Seismic Performance of Bridge Piers which were Retrofitted and Unretrofitted in the Hyogoken Nanbu Earthquake," 131-3, pp. 17-23, Bridges and Foundations

Seible, F. (1999), "Large/Full-Scale Laboratory Validation of Seismic Bridge Design and Retrofit Concepts," Proc. Int. Workshop on Mitigation of Seismic Effects on Transportation Struct. (Loh, C. H. et al editors), 231241, Nat. Center for Res. Earthq. Eng., Taipei, Taiwan, R.O.C.

T.N.Z. (1994), Bridge Manual, Transit New Zealand, New Zealand.

Tamura, K. and Azuma, T. (1997), "Experimental Study of the Effects of Liquefaction-Induced Ground Flow on Bridge Foundation," Proc. 13th US-Japan Bridge Eng. Workshop, US-Japan Panel on Wind and Seismic Effects, UJNR, Tsukuba, Japan

Tamura, K., Azuma, T. and Hamada, T. (2000), "Seismic Design of Bridge Foundations against LiquefactionInduced Ground Flow," 12WCEE, Auckland, New Zealand

Unjoh, S., Terayama, T., Adachi, Y. and Hoshikuma, J. (1997), "Seismic Retrofit of Existing Highway Bridges in Japan", Proc. 29th Joint Meeting, U.S.-Japan Panel on Wind and Seismic Effects, UJNR, pp 161-178

Wakui, H. and Matsumoto, N. (1997), "Seismic Retrofit of Railway Bridges by Means of Carbon Fiber," Civil Engineering, Vol. 82, JSCE, 10-12, Tokyo, Japan 